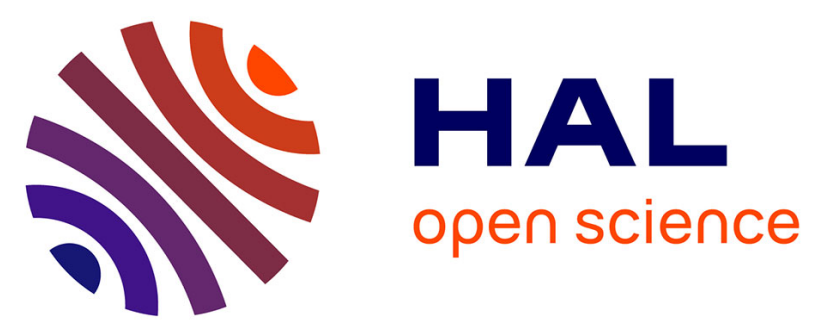

\title{
Mapping the Spatiotemporal Distribution of Acid and Moisture in Food Structures during Gastric Juice Diffusion Using Hyperspectral Imaging
}

Geeshani Somaratne, Marlon M. Reis, Maria J. Ferrua, Aiqian Ye, Francoise Nau, Juliane Floury, Didier Dupont, R. Paul Singh, Jaspreet Singh

\section{To cite this version:}

Geeshani Somaratne, Marlon M. Reis, Maria J. Ferrua, Aiqian Ye, Francoise Nau, et al.. Mapping the Spatiotemporal Distribution of Acid and Moisture in Food Structures during Gastric Juice Diffusion Using Hyperspectral Imaging. Journal of Agricultural and Food Chemistry, 2019, 67, 10.1021/acs.jafc.9b02430 . hal-02267849

\section{HAL Id: hal-02267849 \\ https://hal.science/hal-02267849}

Submitted on 19 Aug 2019

HAL is a multi-disciplinary open access archive for the deposit and dissemination of scientific research documents, whether they are published or not. The documents may come from teaching and research institutions in France or abroad, or from public or private research centers.
L'archive ouverte pluridisciplinaire HAL, est destinée au dépôt et à la diffusion de documents scientifiques de niveau recherche, publiés ou non, émanant des établissements d'enseignement et de recherche français ou étrangers, des laboratoires publics ou privés. 


\title{
Mapping the Spatiotemporal Distribution of Acid and Moisture in Food Structures during Gastric Juice Diffusion Using Hyperspectral Imaging
}

\author{
Geeshani Somaratne, ${ }^{\dagger \dagger}$ Marlon M. Reis, ${ }^{*}, \S$ Maria J. Ferrua, ${ }^{\dagger, \perp}$ Aiqian Ye, ${ }^{\dagger}$ Francoise Nau, ${ }^{\Perp}$ \\ Juliane Floury," Didier Dupont,,$\| \odot$ R. Paul Singh, ${ }^{\dagger, \#}$ and Jaspreet Singh ${ }^{*},, \oplus \odot$ \\ ${ }^{\dagger}$ Riddet Institute, Massey University, Palmerston North, 4442, New Zealand \\ ${ }^{\ddagger}$ School of Food and Advanced Technology, Massey University, Palmerston North, 4442, New Zealand \\ ${ }^{\S}$ Food \& Biobased Products, AgResearch Limited, Palmerston North, 4442, New Zealand \\ ${ }^{\perp}$ Fonterra Research and Development Centre, Palmerston North, 4442, New Zealand \\ "STLO, INRA, AGROCAMPUS OUEST, 35042, Rennes, France \\ ${ }^{\#}$ University of California, Davis, California United States
}

Supporting Information

ABSTRACT: This study investigated the feasibility of using hyperspectral imaging (HSI) to characterize the diffusion of acid and water within food structures during gastric digestion. Two different sweet potatoes (steamed and fried) and egg white gel ( $\mathrm{pH} 5$ and $\mathrm{pH} 9$ EWGs) structures were exposed to in vitro gastric digestion before scanning by HSI. Afterward, the moisture or acid present in the digested sample was analyzed for calibration purposes. Calibration models were subsequently built using partial least-squares (PLS). The PLS models indicated that the full-wavelength spectral range $(550-1700 \mathrm{~nm}) \mathrm{had}$ a good ability to predict the spatial distribution of acid $\left(R_{\mathrm{cal}}^{2}>0.82\right)$ and moisture $\left(R_{\mathrm{cal}}^{2}>0.88\right)$. The spatiotemporal distributions of moisture and acid were mapped across the digested food, and they were shown to depend on the food composition and structure. The kinetic data revealed that the acid and moisture uptakes are governed by Fickian diffusion or by both diffusion and erosion-controlled mechanisms.

KEYWORDS: diffusion, hyperspectral imaging, sweet potatoes, egg white gels, partial least-squares

\section{INTRODUCTION}

Gastric secretion from the stomach is an important biological fluid in the entire digestive system. ${ }^{1}$ It is an acidic and diluted aqueous solution containing electrolytes and digestive enzymes (e.g., pepsin and lipase). ${ }^{2-4}$ The average $\mathrm{pH}$ of gastric acid secreted from the stomach wall of healthy humans is around $\mathrm{pH}$ 2 , which is controlled by hydrochloric acid. ${ }^{5}$ During digestion, gastric moisture and acid contribute to hydration and acid hydrolysis of food, respectively, and thereby alter the external attributes (e.g., softening of the food matrix) and the internal attributes (e.g., chemical composition, $\mathrm{pH}$ ) of the food structure. ${ }^{6,7}$ Thus, the mobility of gastric juice within food matrices in the gastric environment is one of the fundamental parameters that contribute to overall food disintegration and nutrient release during gastric digestion. ${ }^{2}$ Nevertheless, the mechanism by which the diffusion of moisture and acid of the gastric juice affect disintegration of food is still far from being fully understood. ${ }^{2,4}$

Classical characterizations of moisture and acid penetration in food systems during gastric juice diffusion have employed integral gravimetric techniques. As examples, previous studies have focused on identifying the gastric acid and/or moisture diffusion coefficient of different food matrices including rice, ${ }^{7}$ cooked sweet potatoes ${ }^{2,4}$ and frankfurters ${ }^{8}$ using an oven drying method and potentiometric titration, respectively. In these studies, the transport of gastric components into food matrix during gastric digestion were typically characterized by moisture or acid gain into the food product from the surrounding experimental gastric environment using the Fick's second law of diffusion. ${ }^{2,4,7,8}$ While the calculated diffusivity value describes on overall gastric juice gain over digestion time, it does not represent any spatial information in regard to the diffusion process. Furthermore, gastric juice diffusion as a function of time is often insufficient to allow the investigation of the underlying mechanism of moisture or acid penetration during gastric digestion, particularly in heterogeneous food systems., 10

Thus, to gain insight into spatiotemporal gastric juice migration, the diffusion of gastric juice into different food products such as white potatoes, ${ }^{10}$ carrots, and cheese ${ }^{9}$ has been characterized based on an optical image analysis technique. In these studies, the intensity of methylene blue color is used to detect the spatial and temporal changes in gastric fluid distribution allowing it to be indirectly modeled by the Fick's second law. ${ }^{10}$ However, the use of methylene blue and similar colored dyes as reliable indicators of gastric juice has remained unanswered. Alternatively, Kong et al., ${ }^{6}$ studied the spatial and temporal distribution of gastric juice and swelling of peanuts

Received: April 17, 2019

Revised: July 9, 2019

Accepted: July 15, 2019

Published: July 15, 2019 


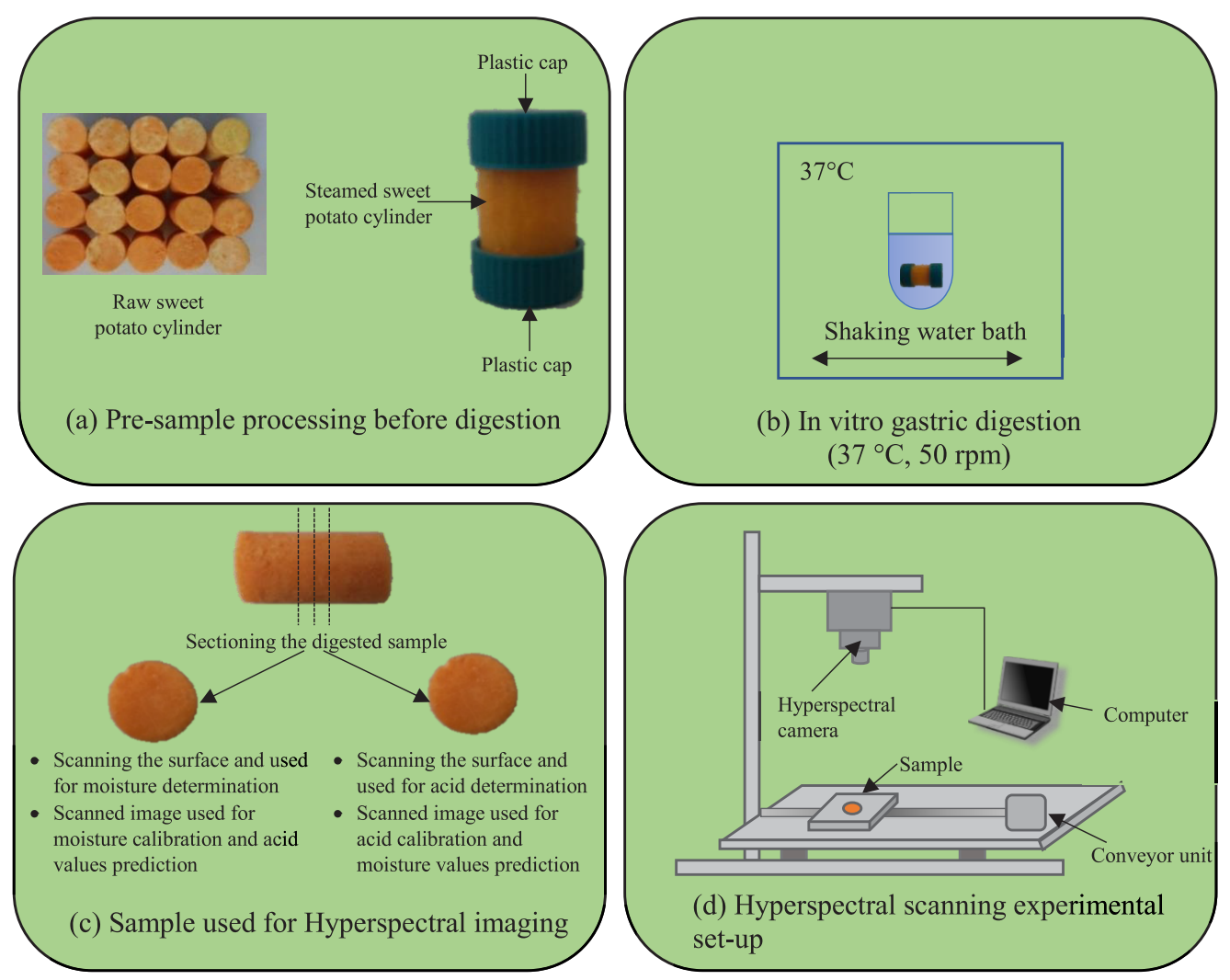

Figure 1. Schematic diagram of the gastric acid and moisture diffusion and hyperspectral scanning experimental procedure of steamed sweet potatoes as an example.

during gastric digestion using the magnetic resonance imaging (MRI) technique. MRI has significant advantages compared to the optical imaging method for the characterization of gastric juice diffusion process because it relies on the characteristic absorption and emission of energy from corresponding protons in the digested sample. ${ }^{11}$ Therefore, MRI does not require the use of added dyes or labeling methods for visualization of different chemical components in the gastric fluid. ${ }^{6}$

Similar to MRI, hyperspectral imaging (HSI) is a labeling free analytical approach used in the food science related research, which is becoming increasingly important in revealing the spatiotemporal distribution of chemical composition within foods. HSI obtains the electromagnetic spectrum for each pixel in the tested image, and this information then creates a threedimensional data set, which can be analyzed to characterize the physical and chemical topographies of the product being scanned. ${ }^{12}$ HSI is used to predict the spatial distribution of sucrose, caffeine, and trigonelline in single green coffee beans, ${ }^{13}$ moisture in red meat, ${ }^{14,15}$ and moisture in dehydrated prawns. ${ }^{16}$ Moreover, the distribution of acid and moisture in a vinegar culture during solid-state fermentation was successfully distinguished with this technique by noting the spectral differences between each component. ${ }^{17}$ The success of these studies inspired us to apply a similar technique of HSI to obtain quantitative information about the spatiotemporal distribution of gastric fluid components in a food matrix. To our knowledge, no study has been reported on the usage of the HSI technique to evaluate the gastric juice diffusion phenomenon during gastric digestion.

The main aim of this study was to explore the feasibility of HSI, in the range $550-1700 \mathrm{~nm}$, for predicting total acid and moisture distributions in food matrices during in vitro gastric juice diffusion process using partial least-squares (PLS) regression models. Consequently, these models can be used to visualize the distribution of acid and moisture within the digestive food matrix at a single pixel level. Steamed and fried sweet potatoes were selected as carbohydrate-based product models whereas two differently structured egg white gels $(\mathrm{pH} 5$ and $\mathrm{pH} 9$ EWGs) were used as protein-based model foods to identify the effect of the material properties (e.g., composition and structure) of solid foods on the diffusion of gastric acid and moisture into the food matrix in the gastric environment.

\section{MATERIALS AND METHODS}

Materials. Sweet potatoes (Beauregard orange variety of Kumara) and fresh eggs were purchased from a local supermarket in Palmerston North (NZ). The sweet potatoes and eggs were stored at room temperature $\left(25^{\circ} \mathrm{C}\right)$ and used within 2 days. To reduce the influence of possible variations among the initial samples, the same batch of sweet potatoes and eggs was used for the entire analysis.

The protein concentration of egg white $(10.5 \pm 0.28 \%)$ was determined by the Kjeldahl method. ${ }^{18}$ Pepsin (from porcine gastric mucosa, $\geq 250 \mathrm{U} / \mathrm{mg}$ solid), gastric lipase (from Aspergillus niger $\geq$ $120000 \mathrm{U} / \mathrm{mg}$ solid), and $\alpha$-amylase (from Aspergillus oryzae, $\geq 30 \mathrm{U} /$ $\mathrm{mg}$ ) were used. All chemicals and enzymes were obtained from SigmaAldrich (St. Louis, MO, U.S.A.). The simulated salivary fluid (SSF) and simulated gastric fluid (SGF) were prepared using the electrolyte stock solutions according to the harmonized protocol within the COST INFOGEST Network, described in Minekus et al. ${ }^{3}$

Sample Preparation. Carbohydrate Based Model Food. Cylindrical sweet potato cores with dimensions of $30 \mathrm{~mm}$ length and $20 \mathrm{~mm}$ diameter were cut from sweet potatoes using a cutting bore. Ten cylindrical samples of sweet potatoes were steamed by placing them above boiling water using a steamer pot for $10 \mathrm{~min}$. To prepare fried 
sweet potatoes, 10 cylindrical samples were fried in preheated canola oil $\left(180 \pm 2{ }^{\circ} \mathrm{C}\right)$ for $5 \mathrm{~min}$.

Protein Based Model Food. EWGs were prepared as described previously in Nyemb et al. ${ }^{19}$ Briefly, fresh egg white solution was homogenized using an IKA T-18 Ultra Turrax Digital Homogenizer $(10000 \mathrm{rpm})$ for $1 \mathrm{~min}$. The required quantities of $2 \mathrm{M} \mathrm{HCL}$ or $2 \mathrm{M}$ $\mathrm{NaOH}$ were added to the egg white solution to achieve $\mathrm{pH} 5$ or $\mathrm{pH} 9$, respectively. Finally, Type-1 ultrapure water (Milli-Q, Millipore Corp.) was used to achieve a protein concentration of $10 \%$ in both $\mathrm{pH} 5$ and pH 9 egg white solutions. These solutions were then put in sealed plastic cylindrical containers (inner diameter $20 \mathrm{~mm}$ ) and were heated in a water bath for $60 \mathrm{~min}$ at $80^{\circ} \mathrm{C}$. After heating, the gels were cooled and kept at $4{ }^{\circ} \mathrm{C}$ for $20 \mathrm{~min}$. Then gels were removed from the plastic casings and cut into $30 \mathrm{~mm}$ length using a surgical scalpel blade. Throughout this manuscript, $\mathrm{pH}$ 5-EWG and $\mathrm{pH}$ 9-EWG refer to the EWGs of pH 5 and $\mathrm{pH} 9$, respectively.

The initial parameters such as weight of the sample, diameter, and length for each food structure were listed in Table 1 of the Supporting Information. To achieve a one-dimensional diffusion process and for easy sample preparation, food cylinders were chosen as samples even though the sizes of the food cylinders selected for the diffusion study were larger than the actual size ranges $(0.1 \text { to } 3 \mathrm{~mm})^{20}$ of particulates of what would normally enter the stomach after mastication. In addition to that, a larger size sample was required to achieve the objective of the study because it was necessary that the food samples not completely break down during the $4 \mathrm{~h}$ of gastric digestion period to improve visualization of gastric acid and moisture distribution.

Static in Vitro Digestion Procedure. Before the in vitro gastric digestion study, plastic caps were fixed to the tops and bottoms of the prepared food cylinders using an acid resistant silicon adhesive (Silcoset 158, Acc Silicones, U.K.) to achieve gastric juice diffusion only in the radial direction (Figure 1a).

Food samples were digested according to the harmonized INFOGEST protocol. ${ }^{3}$ Briefly, the sample was first submitted to a 2 min oral phase by mixing the cylindrical food sample with simulated saliva containing $75 \mathrm{U} / \mathrm{mL}$ amylase ( $1 \mathrm{~mL} \mathrm{SSF} / \mathrm{g}$ food sample) using a $37{ }^{\circ} \mathrm{C}$ shaking water bath (BS-11, Lab Companion) at $50 \mathrm{rpm}$. Subsequently, the sample was mixed with SGF containing pepsin (2000 $\mathrm{U} / \mathrm{mL}$ ) and lipase $(120 \mathrm{U} / \mathrm{mL})$. As shown in Figure $1 \mathrm{~b}$, the sample was then placed inside the shaking water bath $\left(37^{\circ} \mathrm{C}, 50 \mathrm{rpm}\right)$. The $\mathrm{pH}$ values of the soaked samples were immediately adjusted to a value of 3.0. A mass ratio of 1:10 between the food sample and gastric fluid was used to avoid significant changes of gastric juice volume and $\mathrm{pH}$ during the experiments. ${ }^{21}$

Separate samples were prepared for each digestion time of $0,10,20$, $40,60,120,180$, and $240 \mathrm{~min}$, respectively. The maximum digestion time of $240 \mathrm{~min}$ was selected to cover residence time for gastric exposure as most solids are emptied within 3-4 h. ${ }^{22}$ Simulated digestions were performed in triplicate for each food system and digestion time point. After being digested, cylindrical samples were removed from the digestive fluid and two slices $(5 \pm 0.5 \mathrm{~mm}$ of thickness) were obtained from the central parts of each digested food using a surgical scalpel blade. As illustrated in Figure 1c, two slices from food cylinders of one digestion time were used, one for calibration of moisture or acid and the other for prediction. Two different slices belonging to the same cut surface of the digested food cylinder at each digestion time were scanned with a HSI system described below. After scanning, one set of slices was used to determine the moisture whereas the other set of slices was used to determine the acid content using the laboratory method described below.

Hyperspectral Image Acquisition. A schematic diagram of the hyperspectral scanning experimental setup is shown in Figure 1d. The HSI system used in this study includes a computer controlled movable stage, with data acquisition and control software of Hyperspec III, a VIS-InGaAs hyperspectral camera which acquires 235 bands in the spectral range from 548 to $1701 \mathrm{~nm}$, and a Headwall spectrograph (Model 1003B-10151, Headwall Photonics, Fitchburg, MA, U.S.A.) attached to the hyperspectral camera. An optical fiber illumination liner (12" Light line, A08905, Schott Lighting and Imaging) was used to illuminate the sample. A $35 \mathrm{~mm}$ lens with an $\mathrm{f} / \mathrm{stop}$ of 1.65 was placed in front of the hyperspectral camera (exposure time of $34 \mathrm{~ms}$ ) with a frame period of $40 \mathrm{~ms}$ and a translation speed of $6 \mathrm{~mm} / \mathrm{s}$, resulting in a square pixel size of $0.14 \mathrm{~mm} \times 0.14 \mathrm{~mm}$.

The digested slice of the food was placed in the sample holder and transported to a conveyor unit. When the sample moved within the field of view at a constant speed of $2.08 \mathrm{~mm} / \mathrm{s}$, the images and spectra were acquired by the hyperspectral camera and sent to the computer for storage and post processing. The obtained raw images were calibrated automatically by the system using a white and a dark reference image. The white image was obtained by scanning a uniform white Spectralon tile, and the dark reference was obtained with the light off the covering of the lens.

Chemical Analysis of the Digested Samples. Moisture Content Determination. After image acquisition, reference moisture contents of the one food slice ( $5 \pm 0.5 \mathrm{~mm}$ of thickness) at different digestion stages were determined by the thermogravimetric method. The sample was dried in a convective hot-air oven at $105^{\circ} \mathrm{C}$ to constant weight for $16 \mathrm{~h}$. Samples before and after oven drying were weighed. The moisture content was calculated on a wet basis (w.b.). ${ }^{18}$

Total Acid Content Determination. After image acquisition, reference total acid content (in terms of $\mathrm{mg}$ of $\mathrm{HCl} / \mathrm{g}$ sample) of another digested food slice ( $5 \pm 0.5 \mathrm{~mm}$ of thickness) at different digestion stages was determined by potentiometric titration. ${ }^{2}$ First, each slice of the sample was weighed and mixed with $20 \mathrm{~mL}$ of deionized water. The mixture was homogenized at $4600 \mathrm{rpm}$ for $5 \mathrm{~min}$. The initial $\mathrm{pH}$ of the homogenized sample was measured using a portable $\mathrm{pH}$ meter. Potentiometric titrations were performed to measure sample acidity by adding sodium hydroxide $(0.01 \mathrm{~N} \mathrm{NaOH})$ until the sample reached a $\mathrm{pH}$ of $8.2 \pm 0.05$.

Hyperspectral Images Preprocessing. The acquired hyperspectral images were saved in a raw format as a three-dimensional (3-D) hypercube consisting of two spatial dimensions $(x=180$ pixels and $y=$ 320 pixels $)$ and one spectral dimension $(\lambda=235$ bands) from which both the physical and the chemical properties of the samples could be obtained. The initial stage in the hyperspectral image process was the reduction of the data set by removal of background data and retention of key qualitative data (food slice or region of interest) using a principal component analysis (PCA). The resulting image spectra were processed to reduce scattering effects, using standard normal variate (SNV), the Savitzky-Golay smoothing process, and multiplicative scatter correction (MSC). ${ }^{13,17}$ For each food slice image, the mean spectrum was extracted by averaging the spectra of each pixel in the region of interests. The mean spectral data for each sample were used in the next stage of the analysis. The Prediktera Evince software 2.7.2 (Prediktera $\mathrm{AB}$, Umeå, Sweden) was used for the preprocessing of images and mean spectrum extraction.

Model Development to Predict Moisture and Acid Distribution. Among the 48 scanned samples from each food system (two food slices from one replicate $\times 8$ digestion times $\times 3$ replicates), samples were divided into two sample sets such as a calibration set and a prediction set. A calibration sample set consisted of 24 samples (first food slice from one replicate $\times 8$ digestion times $\times 3$ replicates). The mean spectra obtained were linked to the reference moisture or acid contents of digested food slice using a PLS regression analysis to develop a calibration model. Thus, the calibration sample set was used for developing the PLS regression model. A full cross-validation (leaveone-out) method was applied to the calibration set to determine the optimal number of latent variables (LVs). Then, this calibration model was applied to the prediction sample set which consisted of 24 samples (corresponding second food slice from one replicate $\times 8$ digestion times $\times 3$ replicates). The prediction set was used for model validation and verification of the prediction performance of the calibration models. The development of the calibration and prediction models were performed using the Prediktera Evince software 2.7.2 (Prediktera $\mathrm{AB}$, Umeå, Sweden). Performance of the calibration and prediction models were evaluated using several statistical parameters, including coefficient of correlation $\left(R^{2}\right)$ between measured and predicted value, root-mean-square error (RMSE) of calibration (RMSEC), RMSE of prediction (RMSEP), and the number of latent variables. A good model should have a high $R^{2}$ and a low RMSE. ${ }^{13-15}$ In addition to that, a good 
Table 1. Moisture Contents (\% Wet Basis) of Sweet Potatoes and EWGs during 240 min of in Vitro Gastric Digestion ${ }^{a}$

\begin{tabular}{|c|c|c|c|c|c|c|c|c|}
\hline \multirow[b]{2}{*}{ Food type } & \multicolumn{8}{|c|}{ Digestion time (minute) } \\
\hline & 0 & 10 & 20 & 40 & 60 & 120 & 180 & 240 \\
\hline SSP & $83.75 \pm 1.44^{\mathrm{Bc}}$ & $83.87 \pm 0.41^{\mathrm{Bc}}$ & $84.90 \pm 0.41^{\mathrm{Ab}}$ & $85.82 \pm 0.21^{\mathrm{Ab}}$ & $86.12 \pm 0.31^{\mathrm{Ab}}$ & $86.67 \pm 0.68^{\mathrm{Ab}}$ & $87.28 \pm 0.61^{\mathrm{Ba}}$ & $88.09 \pm 0.26^{\mathrm{Ba}}$ \\
\hline FSP & $71.00 \pm 5.28^{\mathrm{Cd}}$ & $70.46 \pm 4.41^{\mathrm{Cd}}$ & $75.97 \pm 0.60^{\mathrm{Bd}}$ & $84.39 \pm 1.55^{\mathrm{Abc}}$ & $84.85 \pm 4.37^{\mathrm{Ab}}$ & $89.49 \pm 2.00^{\mathrm{Aab}}$ & $90.91 \pm 7.38^{\mathrm{Aab}}$ & $94.34 \pm 1.65^{\mathrm{Aa}}$ \\
\hline pH 5-EWG & $87.66 \pm 0.13^{\mathrm{Ab}}$ & $87.79 \pm 0.10^{\mathrm{Ab}}$ & $88.44 \pm 0.01^{\mathrm{Aa}}$ & $88.70 \pm 0.06^{\mathrm{Aa}}$ & $88.75 \pm 0.07^{\mathrm{Aa}}$ & $88.73 \pm 0.10^{\mathrm{Aa}}$ & $88.75 \pm 0.04^{\mathrm{Ba}}$ & $88.78 \pm 0.04^{\mathrm{Ba}}$ \\
\hline pH 9-EWG & $87.89 \pm 0.40^{\mathrm{Ab}}$ & $88.34 \pm 0.09^{\mathrm{Aa}}$ & $88.28 \pm 0.21^{\mathrm{Aab}}$ & $88.67 \pm 0.09^{\mathrm{Aa}}$ & $88.33 \pm 0.15^{\mathrm{Aa}}$ & $88.52 \pm 0.13^{\mathrm{Aa}}$ & $88.17 \pm 0.44^{\mathrm{Ba}}$ & $88.60 \pm 0.17^{\mathrm{Ba}}$ \\
\hline
\end{tabular}

${ }^{a}$ Values represent averages $(n=3) \pm$ standard deviation. SSP: steamed sweet potateos, FSP: fried sweet potatoes. A-C: means within each column followed by different superscript letters are significantly different $(p<0.05)$. a-d: means within each line followed by different superscript letters are significantly different $(p<0.05)$.

Table 2. Acid Contents ( $\mathrm{mg} \mathrm{HCl} / \mathrm{g}$ of Sample) of Sweet Potatoes and EWGs during 240 min of in Vitro Gastric Digestion ${ }^{a}$

\begin{tabular}{|c|c|c|c|c|c|c|c|c|}
\hline \multirow[b]{2}{*}{ Food type } & \multicolumn{8}{|c|}{ Digestion time (minute) } \\
\hline & 0 & 10 & 20 & 40 & 60 & 120 & 180 & 240 \\
\hline SSP & $0.86 \pm 0.07^{\mathrm{Be}}$ & $0.86 \pm 0.04^{\mathrm{Be}}$ & $0.88 \pm 0.19^{\text {Bed }}$ & $1.11 \pm 0.06^{\mathrm{Bd}}$ & $1.26 \pm 0.07^{\mathrm{Bb}}$ & $1.20 \pm 0.05^{\mathrm{Bcb}}$ & $1.34 \pm 0.03^{\mathrm{Bb}}$ & $1.47 \pm 0.06^{\mathrm{Ba}}$ \\
\hline FSP & $1.04 \pm 0.23^{\mathrm{Af}}$ & $1.25 \pm 0.29^{\mathrm{Ae}}$ & $1.45 \pm 0.27^{\text {Ade }}$ & $1.63 \pm 0.26^{\mathrm{Ac}}$ & $1.77 \pm 0.18^{\mathrm{Abc}}$ & $1.91 \pm 0.26^{\mathrm{Aab}}$ & $1.86 \pm 0.36^{\mathrm{Aab}}$ & $2.25 \pm 0.22^{\mathrm{Aa}}$ \\
\hline pH5-EWG & $1.11 \pm 0.02^{\mathrm{Ac}}$ & $1.13 \pm 0.01^{\mathrm{Ac}}$ & $1.19 \pm 0.05^{\mathrm{Bbc}}$ & $1.26 \pm 0.04^{\mathrm{Bb}}$ & $1.27 \pm 0.04^{\mathrm{Bb}}$ & $1.31 \pm 0.03^{\mathrm{Bab}}$ & $1.33 \pm 0.02^{\mathrm{Ba}}$ & $1.32 \pm 0.02^{\mathrm{Ba}}$ \\
\hline pH9-EWG & $0.00 \pm 0.00^{\mathrm{Ca}}$ & $0.01 \pm 0.02^{\mathrm{Ca}}$ & $0.08 \pm 0.01^{\mathrm{Ca}}$ & $0.14 \pm 0.01^{\mathrm{Ca}}$ & $0.17 \pm 0.01^{\mathrm{Ca}}$ & $0.14 \pm 0.05^{\mathrm{Ca}}$ & $0.13 \pm 0.02^{\mathrm{Ca}}$ & $0.16 \pm 0.02^{\mathrm{Ca}}$ \\
\hline
\end{tabular}

${ }^{a}$ Values Represent Averages $(\mathrm{n}=3) \pm$ Standard Deviation. SSP: steamed sweet potateos, FSP: fried sweet potatoes. A-C: means within each column followed by different superscript letters are significantly different $(p<0.05)$. a-f: means within each line followed by different superscript letters are significantly different $(p<0.05)$.

model also should have a lower number of LVs than the number of samples. ${ }^{13-15}$

Visualization and Prediction of the Spatiotemporal Distribution of Acid and Moisture. With the help of the developed PLS models, the total acid and moisture contents of each pixel in the hyperspectral image were predicted and their spatial distributions were shown with linear color scales. For predicting moisture and acid contents in all pixels of the sample, the developed PLS model for each food system was transferred to each pixel of the image. After multiplying the model's regression coefficient by the spectrum of each pixel in the image, a prediction chemical image was built which exhibited the spatial distribution of total acid and moisture of the sample. The resulting chemical images are generally referred to as the "distribution map"14 which was generated using the Prediktera Evince software 2.7.2 (Prediktera AB, Umeå, Sweden).

During the visualization process, each pixel in the digested food matrix image was assigned to a specific color from the HSV color space, based on predicted moisture or acid content for that pixel, which facilitated the elucidation of the moisture or acid diffusion processes. Note that each product model has a different range of moisture or acid distribution during gastric digestion. Instead of using the same color scale for each product model, a color scale with different ranges of moisture or acid contents of an individual food structure was used to represent hyperspectral images. This helped to clearly identify the spatiotemporal distribution patterns of gastric acid or moisture within the food structure during gastric digestion.

Finally, the predicted spatiotemporal distributions of acid and moisture values of the digested samples were generated. The average acid and moisture contents of each sample (average of acid and moisture contents of pixel in the region of interest) were determined as a function of digestion times using the Evince 2.7.0 hyperspectral image analysis software package (Prediktera AB, Umeå, Sweden).

Acid and Moisture Diffusion Modeling. To study the kinetics and mechanisms of acid and moisture diffusion from the selected product models, two different kinetic models were considered to fit the experimental data. The experimental data fitting was carried out using nlinfit, a nonlinear regression function in Matlab (R2016a, U.S.A.).

Fick's Second Law. Considering that the model food behaves like an infinite cylinder, a theoretical model (eq 1) based on Fick's second law was applied, considering the following assumptions: (i) negligible external resistance to mass transfer; (ii) isotropic and homogeneous material; (iii) negligible material shrinkage. ${ }^{23}$ The experimental concentration ratio (CR) results were applied to fit the following analytical solution of Fick's second law for obtaining the value of the effective diffusivity $\left(D_{\text {eff }}\right)$.

$$
\mathrm{CR}=\frac{C_{\mathrm{e}}-C_{(\mathrm{t})}}{C_{\mathrm{e}}-C_{0}}=\frac{4}{\pi^{2}} \sum_{n=1}^{\infty} \frac{\pi^{2}}{R^{2} \delta n^{2}} \exp \left(-D_{\text {eff }} t \delta_{n}{ }^{2}\right)
$$

where $\mathrm{CR}$ is the acid or water concentration ratio, $C_{(t)}$ is the concentration of acid or water $\left(\mathrm{mg} \mathrm{HCl} / \mathrm{g}\right.$ of sample or $\mathrm{g} \mathrm{H}_{2} \mathrm{O} / \mathrm{g}$ of sample), $\mathrm{C}_{0}$ is the initial concentration $\left(\mathrm{mg} \mathrm{HCl} / \mathrm{g}\right.$ of sample or $\mathrm{g} \mathrm{H}_{2} \mathrm{O}$ / $\mathrm{g}$ of sample), $C_{\mathrm{e}}$ is the equilibrium concentration $(\mathrm{mg} \mathrm{HCl} / \mathrm{g}$ of sample or $\mathrm{g} \mathrm{H}_{2} \mathrm{O} / \mathrm{g}$ of sample), $R$ is the radius of the sample before digestion (m), $t$ is the digestion time (s), $D_{\text {eff }}$ is the effective diffusion coefficient (radial direction, $\left.\mathrm{m}^{2} \mathrm{~s}^{-1}\right)$, and $\delta_{n}$ is the Bessel function root $(n=100)$. To prove negligible material shrinkage, the changes in diameter after gastric digestion for each food structure were listed in Table 2 of the Supporting Information.

Power Law Model (Ritger-Peppas Model). The mechanism and kinetics of moisture and acid diffusion during gastric digestion were deduced from the fitting of the experimental acid or moisture CR to the Ritger-Peppas model. ${ }^{24}$ It is based on the power law and widely used to describe profiles of water diffusion into high-amylose starch tablets. $25-27$

$$
\mathrm{CR}=\frac{C_{\mathrm{e}}-C_{(\mathrm{t})}}{C_{\mathrm{e}}-C_{0}}=k t^{n}
$$

where $t$ is the digestion time, $k$ is a parameter related to the velocity of the diffusion, and $n$ is the diffusional exponent, which indicates the diffusion mechanism. For cylinders, when $n<0.45$, the diffusion mechanism can be hypothesized as purely Fickian diffusion. When 0.45 $<n<0.89$, the transport mechanisms are hypothesized to be both Fickian diffusion and erosion controlled mechanism. When the value of $n$ is greater than 0.89 , a pure erosion controlled mechanism is generally observed. $^{24,26}$

Statistical Analysis. An analysis of variance was conducted using a 2 -factor factorial design to determine differences in acid and moisture uptake during simulated gastric digestion. The factors were food types (steamed sweet potatoes, fried sweet potatoes, $\mathrm{pH}$ 5-EWG, and $\mathrm{pH}$ 9EWG) and digestion time (0-240 min). A one-way analysis of variance was used to assess differences in Fick's second law and the power law model parameters. A Tukey multiple comparison test was implemented to investigate the differences among means when the main effects were significant. Minitab 17 software was used for statistical analysis. 


\section{RESULTS AND DISCUSSION}

Moisture and Acid Content Change during Gastric Digestion. Moisture and acid content were significantly influenced by food type, digestion time, and their interaction $(p<0.05$, Tables 1 and 2 respectively). Fried sweet potatoes had the lowest initial moisture compared to the other foods $(71.0 \%$ compared to $<87.9 \%$ ). Fried sweet potatoes and $\mathrm{pH} 5$-EWG exhibited comparatively high acid content whereas $\mathrm{pH}$ 9-EWG had no initial acid compared to the other foods $(0.0 \mathrm{mg} \mathrm{HCl} / \mathrm{g}$ of the sample compared to $<1.1 \mathrm{mg} \mathrm{HCl} / \mathrm{g}$ of the sample). Steamed and fried sweet potatoes had significant increases in moisture and acid contents during the 240 min gastric digestion period $(p<0.05)$. However, despite the gradual increase in moisture and acid contents over the 240 min digestion period, no significant $(p<0.05)$ changes in moisture and acid contents during digestion were observed for $\mathrm{pH}$ 5-EWG and $\mathrm{pH}$ 9-EWG.

Moisture Content Prediction. Table 3 shows the main statistics used to evaluate the performance of the developed

Table 3. Performance of the PLS Regression Model for Moisture Content for HSI Quantification on Different Food Samples $^{a}$

\begin{tabular}{lcccccc} 
& & \multicolumn{2}{c}{ Calibration } & & \multicolumn{2}{c}{ Prediction } \\
\cline { 3 - 4 } Steamed sweet potatoes & 4 & 0.90 & 0.48 & & 0.87 & 0.71 \\
Fried sweet potatoes & 3 & 0.90 & 0.27 & & 0.83 & 0.42 \\
pH 5-EWG & 3 & 0.91 & 0.13 & & 0.83 & 0.19 \\
pH 9-EWG & 4 & 0.88 & 0.11 & & 0.80 & 0.16
\end{tabular}

${ }^{a}$ LVs: latent variables. Sample size $(n): 24$. Spectral range: $550-1700$ nm. $R_{\text {cal }}^{2}=$ coefficient of determination of calibration, $R_{\text {pred }}{ }^{2}=$ coefficient of determination of prediction, RMSEC = root-meansquare error of calibration, RMSEP = root-mean-square error of prediction.

calibration and prediction models for predicting the moisture contents of the examined food samples. Calibration models generated using hyperspectral data with $R^{2}$ values of greater than 0.70 can be considered as good enough for prediction purposes. $^{13,28}$ Thus, it was observed that the PLS calibration models based on full spectra had a very good $\left(\mathrm{R}_{\mathrm{cal}}{ }^{2}>0.70\right)^{13,28}$ moisture prediction accuracy for all food matrices, with $\mathrm{R}_{\text {cal }}{ }^{2}>$ 0.88 (Table 3 and Figure 2) and RMSEC < 0.48 (Table 3). The predicted versus measured plots for the best PLS calibration models for moisture content are shown in Figure 2. It can be observed that the measured and predicted moisture values of $\mathrm{pH}$ 5-EWG (Figure 2c) are separated into two different regions. This could be because the initial moisture content of the sample (87-88\%) immediately (after $10 \mathrm{~min}$, as seen in Table 1) reached the equilibrium moisture content (88.5-89.0\%) after immersion in the gastric fluid. The application of HSI has been reported previously for moisture determination in biological products (e.g., mango, banana, and strawberry), demonstrating a similar prediction performance of $R^{2} \geq 0.90$ of PLS regression calibration built on the wavelengths of 400 and $1000 \mathrm{~nm} .^{29-31}$

In this study, all PLS models appeared to be acceptable since not more than four factors (LVs) were used in the development of calibration models (Table 3 ). When the calibrated model was used to predict the samples, the prediction results were also desirable, with $R_{\text {pred }}^{2}>0.80$ between the measured and the predicted values for all food types and the RMSEP $<0.71$ for all food types (Table 3).
Acid Content Prediction. The main statistics used to evaluate the performance of the developed calibration and prediction models for predicting moisture content of the examined food samples are given in Table 4. The predicted versus measured plots for the best PLS regression models for acid content are shown in Figure 3. The performance of the PLS model was good $\left(R_{\mathrm{cal}}^{2}>0.7\right)^{13,28}$ for acid prediction in steamed sweet potatoes $\left(R_{\mathrm{cal}}^{2}=0.90\right)$, fried sweet potatoes $\left(R_{\mathrm{cal}}^{2}=0.90\right)$, pH5-EWG $\left(R_{\text {cal }}^{2}=0.87\right)$, and pH9-EWG $\left(R_{\text {cal }}^{2}=0.82\right)$. It was also demonstrated that all calibrated models had good performances with the low RMSEC $<0.15$. The range of $R^{2}$ $(0.82-0.90)$ of the PLS calibration models obtained in this study was comparable to those reported previously by the application of HSI on vinegar culture to investigate their acid content, with $R^{2}$ of the PLS model equal to $0.86 .{ }^{17}$ However, the slight variation of prediction performances of the PLS models among foods could be due to the inherent biological variability among the food matrixes.

The PLS regression model appeared to be robust since less than four factors (LVs) were used in the calibration model development in four different product models (Table 4). When the acid calibrated model was applied to the prediction set, the results were applicable with $R_{\text {pred }}^{2}>0.80$ between the measured and the predicted values for all food types and the RMSEP < 0.25 for all food types (Table 4 ).

Spatiotemporal Distribution of Moisture in Food Structures during Gastric Digestion. The developed PLS regression models for the prediction of moisture in sweet potatoes and EWG model foods were applied to HSI hypercubes to visualize the spatial moisture distribution of digested samples with different digestion times. Figure 4 shows the final visualized image of the moisture distribution of selected product models at eight different gastric digestion times. Although there was variation in the distributions in moisture contents across the different food matrices, there was a general trend of increase in overall moisture content represented by the shift from blue to red (Figure 4). This is an indication of food matrices absorbing moisture during their gastric digestion.

More specifically, the majority of pixels within the steamed sweet potatoes before gastric digestion indicated a high and homogeneous moisture content (83\%) (Figure 4a). When the digestion progressed, the gastric juice diffusion resulted in an isotropic change of the moisture distribution as evidenced by the shift toward the higher end of the scale (i.e., to red). After 240 min of digestion, almost all the pixels were at this end of the scale, corresponding to an average moisture content of $83.3 \%$ to $88.2 \%$.

As shown in Figure $4 \mathrm{~b}$, in comparison to steaming, frying created two different regions within the food matrix before digestion: an outer layer corresponding to the crust that could be easily recorded visually and an interior part or core, in agreement with previous findings. ${ }^{32,33}$ The crust region showed a uniform moisture distribution, with relatively low moisture content $(<50 \%)$. In contrast, the inner core was much wetter with a moisture content higher than $80 \%$. During the digestion process, it is noteworthy that the distinction between these two parts (crust and core) persisted for a long time: both regions were still easily distinguished after $120 \mathrm{~min}$ of digestion. The diffusion process of gastric juice, which can be interpreted as transport in a gradient of concentration, quickly resulted in a very high moisture content (around $90 \%$ as soon as 40 min digestion) in the inner core, whereas the crust remained dryer (around 75\% after 120 min digestion); moisture contents as low as $50 \%$ were 


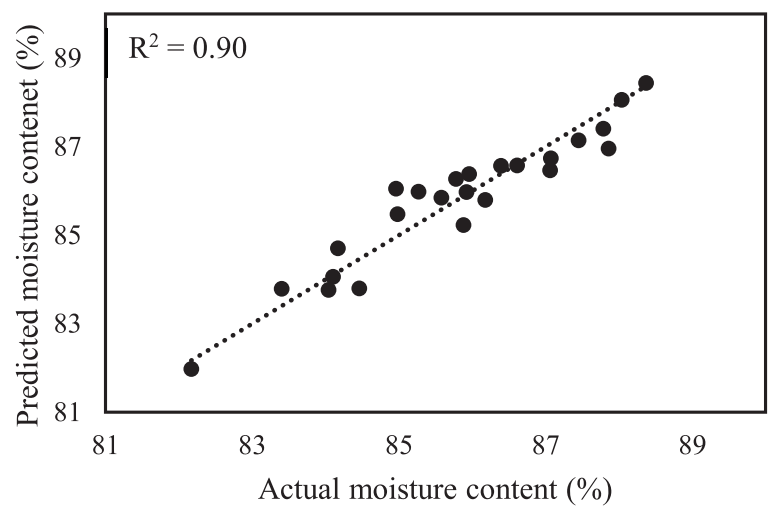

(a)

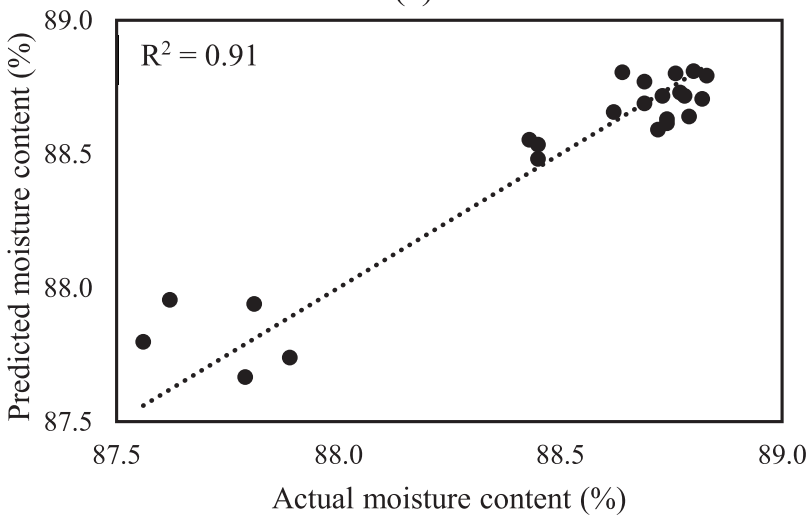

(c)

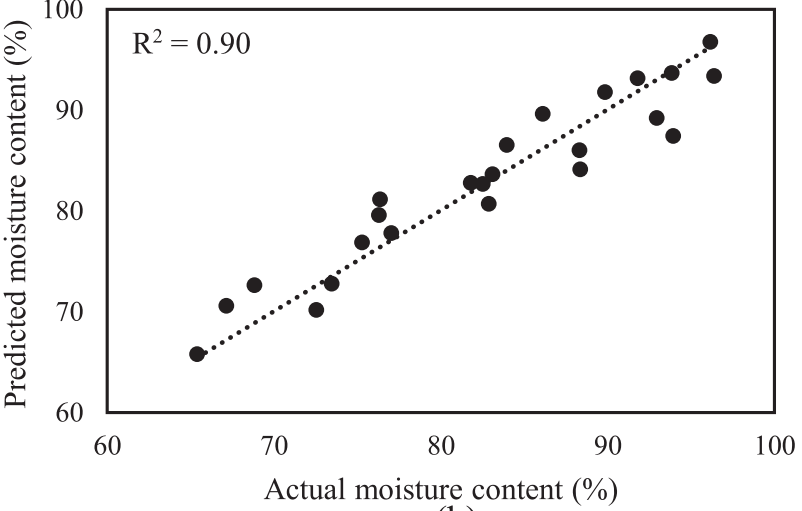

(b)

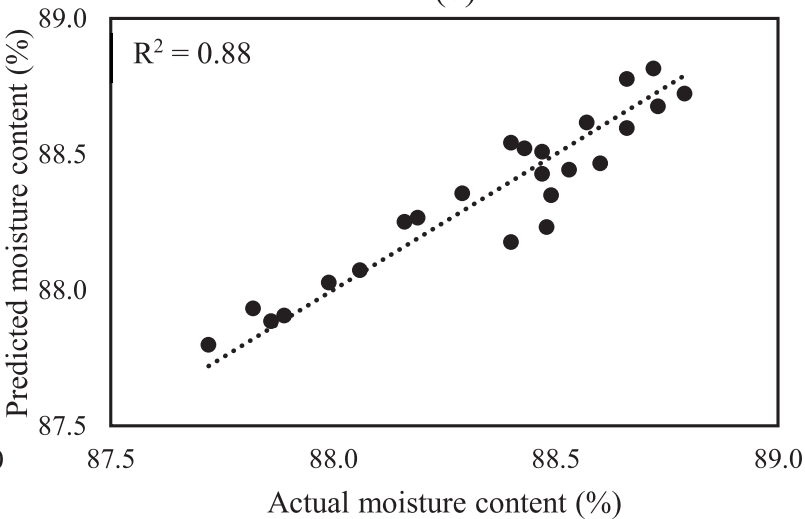

(d)

Figure 2. Predicted versus measured values of moisture in (a) steamed sweet potatoes, (b) fried sweet potatoes, (c) pH5-EWG, and (d) pH9-EWG for the best PLS models (calibration data set), expressing the moisture content as wet basis. The solid line shows the calibration line of the PLS regression model. Performance of the PLS regression model for moisture indicated as the determination coefficients $\left(R^{2}\right)$.

Table 4. Performance of the PLS Regression Model for Acid Content for HSI Quantification on Different Food Samples ${ }^{a}$

\begin{tabular}{lccccccc} 
& & \multicolumn{2}{c}{ Calibration } & & \multicolumn{2}{c}{ Prediction } \\
\cline { 3 - 4 } Steamed sweet potatoes & 4 & & $R_{\text {cal }}^{2}$ & RMSEC & & $R_{\text {pred }}^{2}$ & RMSEP \\
Fried sweet potatoes & 4 & 0.90 & 0.06 & & 0.91 & 0.07 \\
pH5-EWG & 3 & 0.87 & 0.15 & & 0.80 & 0.22 \\
pH9-EWG & 4 & 0.82 & 0.02 & & 0.80 & 0.02
\end{tabular}

${ }^{a}$ LVs: latent variables. Sample size $(n): 24$. Spectral range: $550-1700$ nm. $R_{\text {cal }}{ }^{2}=$ coefficient of determination of calibration, $R_{\text {pred }}^{2}=$ coefficient of determination of prediction, RMSEC = root-meansquare error of calibration, RMSEP = root-mean-square error of prediction.

still locally observed after $180 \mathrm{~min}$ of digestion. This indicates that the crust might be permeable and allows diffusion into the core of the sample. Moreover, in comparison to the moisture content of fried sweet potatoes $(71.0 \pm 5.3 \%)$, the steamed potatoes $(83.8 \pm 1.4 \%)$ have a higher content of moisture at the start; the moisture concentration gradient between gastric medium and the steamed sweet potato is lower and there is a less intense gradient and therefore lower transport of moisture into the product.

In $\mathrm{pH}$ 5-EWG, initially at around $87 \%$ moisture, gastric juice advanced rapidly: a homogeneous and stable moisture content (89\%) was reached after only $20 \mathrm{~min}$ of digestion. This is consistent with the porous nature of this EWG, as previously characterized by Nyemb et al. ${ }^{19}$ and Somaratne et al. ${ }^{29}$ In contrast, the diffusion of moisture into the $\mathrm{pH}$ 9-EWG matrix is slower, the equilibrium being reached after approximately $1 \mathrm{~h}$ of digestion. This is consistent with the more compact and dense microstructure of $\mathrm{pH}$ 9-EWG ${ }^{19,34}$ which might hinder the penetration of gastric moisture.

Spatiotemporal Distribution of Acid in Food Structures during Gastric Digestion. The spatiotemporal distribution of acid in selected food structures during gastric digestion is displayed in Figure 5. A nonuniform acid distribution was observed in nondigested steamed sweet potatoes (Figure 5a). When immersed in the gastric fluid, gastric acid advanced rapidly and anisotropically to the center of the sample, as shown by the blue area of the images. This may be due to the inherent variations including irregular pore path distribution within the cooked sweet potato matrix. ${ }^{2}$ An uneven acid distribution was observed in nondigested fried sweet potatoes, with a lower acid content in the crust region and a higher acid content at the middle of the sample (Figure 5b). Similar to steamed sweet potatoes, upon immersion, a rapid gain of acid was observed in fried sweet potatoes. Moreover, it can be clearly observed that for steamed sweet potatoes and fried sweet potatoes, the patterns of water (Figure $4 \mathrm{a}, \mathrm{b}$ ) and acid (Figure 5 a,b) distributions during gastric digestion were not similar.

Figure $5 \mathrm{c}$ clearly shows that acid diffusion into the $\mathrm{pH}$ 5-EWG matrix is anisotropic in the radial plane. This may be due to the irregular and interconnected pore path distributions within the gel matrix. ${ }^{19,34}$ In $\mathrm{pH}$ 9-EWG, the acid diffusion process can be described as an anisotropical increase over a limited range from 0 to $0.4 \mathrm{mg} \mathrm{HCl} / \mathrm{g}$ of the sample within $4 \mathrm{~h}$ of gastric digestion. This could be because the diffusion of gastric acid may be limited 


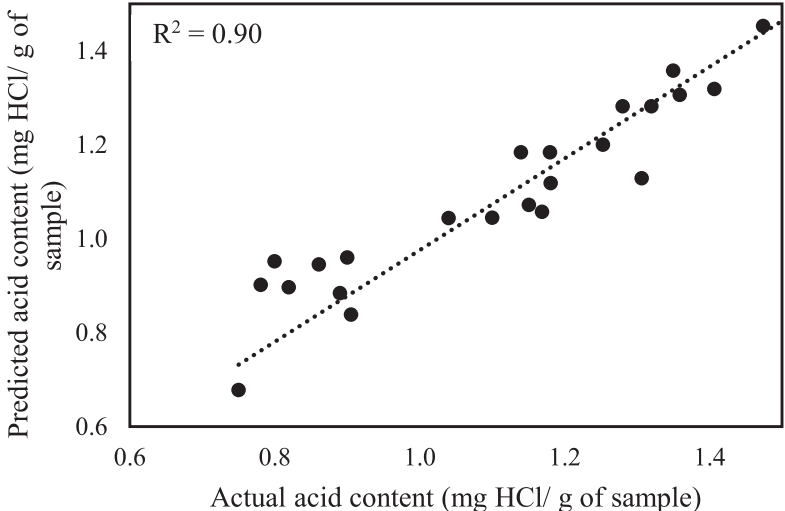

(a)

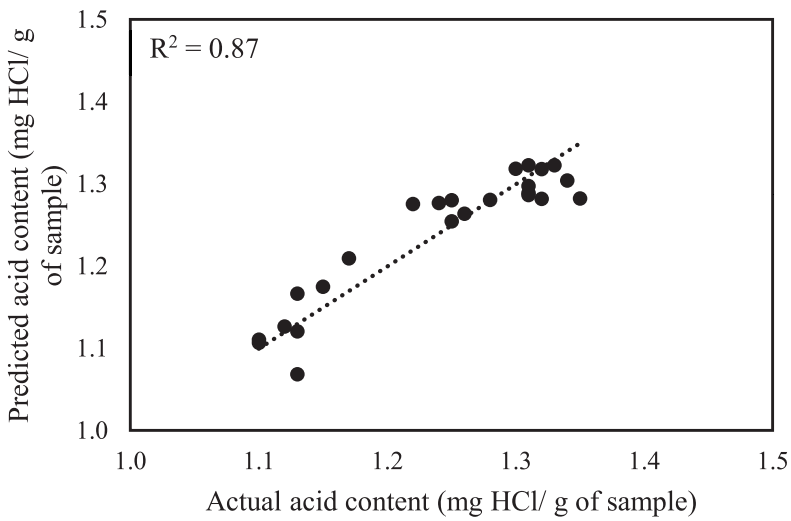

(c)

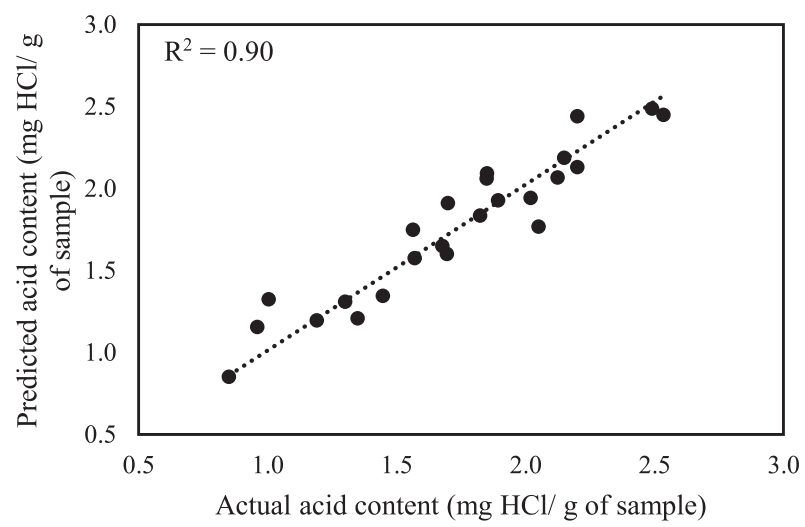

(b)

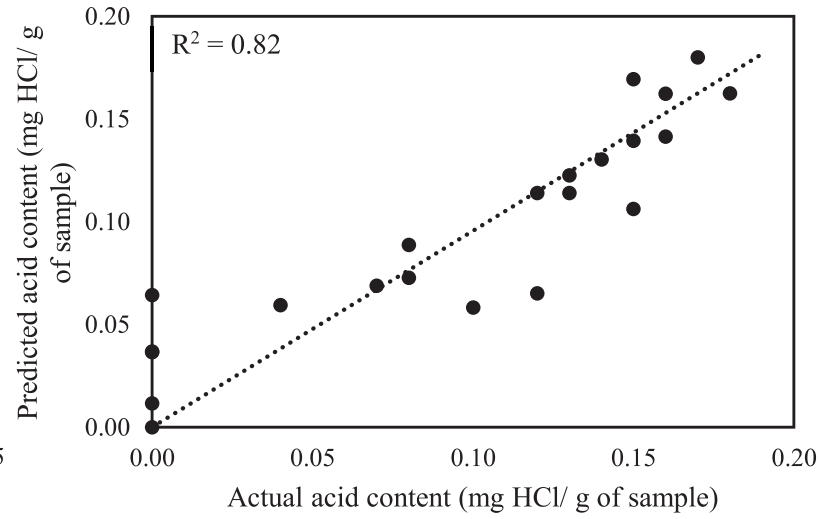

(d)

Figure 3. Predicted versus measured values of acid in (a) steamed sweet potatoes, (b) fried sweet potatoes, (c) pH 5-EWG, and (d) pH 9-EWG for the best PLS models (calibration data set), expressing the acid content as $\mathrm{mg} \mathrm{HCl} / \mathrm{g}$ of sample. The solid line shows the calibration line of the PLS regression model. Performance of the PLS regression model for acid indicated as determination coefficients $\left(R^{2}\right)$.

by the compact and dense nature of $\mathrm{pH} 9-\mathrm{EWG}^{19,34}$ and the negligible initial acid content of the $\mathrm{pH}$ 9-EWG matrix.

Impact of Food Structures on Diffusion Kinetics of Water during Gastric Digestion. Figure 6 illustrates the concentration ratio of moisture uptake into the food structures as a function of digestion time for selected sweet potatoes and EWG product models. The in vitro moisture gain concentration profiles of different food structures could be expressed by the Fick's second law, as the diffusion model provided a good fit for almost all of the data sets $\left(R^{2}>0.91\right)$. The $D_{\text {eff }}$ of gastric moisture was estimated for each food structure and is shown in Table 5 .

The food type significantly affected the diffusion kinetics of moisture during gastric digestion $(p<0.05)$. There is a trend that may show a significantly higher effective water diffusivity in steamed sweet potatoes $\left(D_{\text {eff }}=2.2 \pm 0.8 \times 10^{-9} \mathrm{~m}^{2} / \mathrm{s}\right)$ than fried sweet potatoes $\left(1.9 \pm 0.5 \times 10^{-9} \mathrm{~m}^{2} / \mathrm{s}\right)$. Mennah-Govela and Bornhorst ${ }^{2}$ reported similar trends of diffusion of water in steamed and fried sweet potatoes during gastric juice diffusion.

It can be observed that $\mathrm{pH}$ 5-EWG had considerably ( $p<$ $0.05)$ higher $D_{\text {eff }}$ of water $\left(5.6 \pm 1.4 \times 10^{-9} \mathrm{~m}^{2} / \mathrm{s}\right)$ than $\mathrm{pH} 9$ EWG $\left(2.1 \pm 0.1 \times 10^{-9} \mathrm{~m}^{2} / \mathrm{s}\right)$. At $\mathrm{pH} 5$, which is close to the isoelectric point of most egg white protein, the formation of spherical aggregates of egg white protein is predominant which leads to the formation of porous and spatially heterogeneous structures of the $\mathrm{pH}$ 5-EWG. ${ }^{19,34}$ This loosely packed, more porous, and spatially heterogeneous structure of the $\mathrm{pH}$ 5$\mathrm{EWG}^{19,34}$ allows the water to diffuse at a faster rate. In contrast, $\mathrm{pH}$ 9-EWG has a less porous and a more rigid structure due to the formation of linear aggregates of egg white protein at $\mathrm{pH}$ $9,{ }^{19,34}$ which likely hinders the water mobility within the structure. This fact could be further strengthened using the results reported in our previous studies in which the loosened microstructure in the $\mathrm{pH}$ 5-EWG may lead to faster pepsin diffusion and subsequent gel disintegration compared to the smooth-gel structure of $\mathrm{pH}$ 9-EWG. ${ }^{34,35}$

To confirm the diffusion mechanism, the data were fitted with the power law model. ${ }^{24}$ The model parameters and goodness of fit $\left(R^{2}>0.94\right)$ are shown in Table 5. The water diffusion exponent $(n)$ was found to be higher than 0.45 and lower than 0.89 for the steamed and fried sweet potatoes, which implies that the transfer of water did not follow a pure Fickian diffusion behavior but rather coupled diffusion and erosion mechanisms in both matrices. Hence, diffusion of water due to the concentration gradient coupled with the erosion of food structure due to acid hydrolysis of cellular structure ${ }^{2,4,9}$ might be the predominant mechanisms for the water diffusion in the steamed and fried sweet potatoes during in vitro gastric juice diffusion. Thus, the plant cell wall of steamed and fried sweet potatoes can be degraded by the acid contained in the gastric fluid $^{4}$ which facilitates the diffusion of water in gastric fluid.

However, Figure 4a,b illustrates that hydrolysis of sweet potato food matrix is not predominant because no significant reduction in the steamed or fried food matrix's shape was observed, even after $4 \mathrm{~h}$ of gastric digestion. In addition to that, the diameter changes of steamed and fried sweet potatoes with digestion time is negligible (Table 2). This observation is supported by the previous study. ${ }^{2}$ These authors reported that 


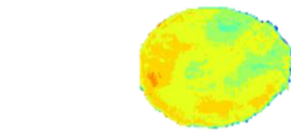

Digestion times 0 mins

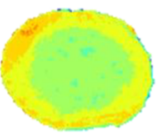

10 mins

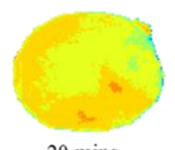

20 mins

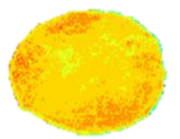

40 mins

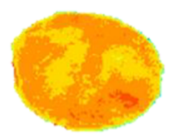

$60 \mathrm{mins}$

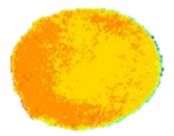

120 mins

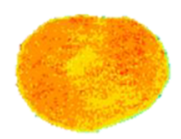

180 mins

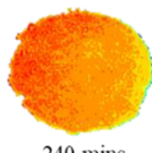

240 mins

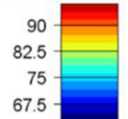

Moisture content (\%)

(a)

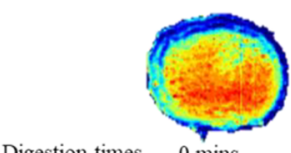

Digestion times

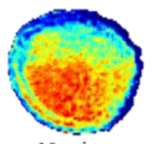

10 mins

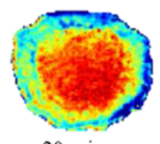

20 mins

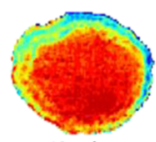

40 mins

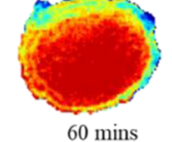

(b)
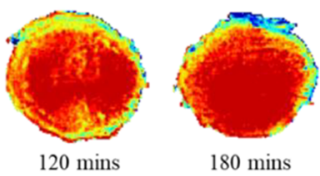

180 mins
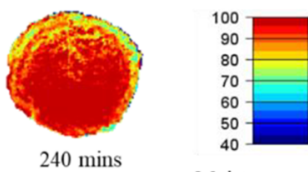

Moisture content (\%)

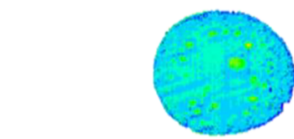

Digestion times

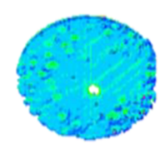

10 mins

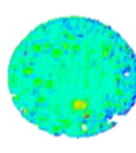

20 mins

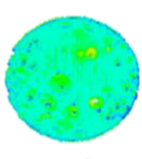

40 mins

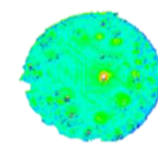

(c)

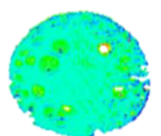

120 mins

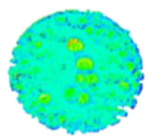

180 mins

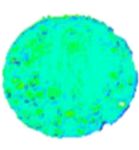

240 mins

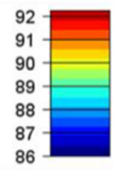

Moisture content (\%)

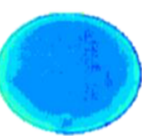

Digestion times

0 mins
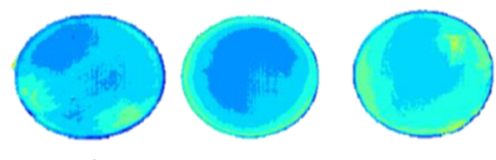

40 mins
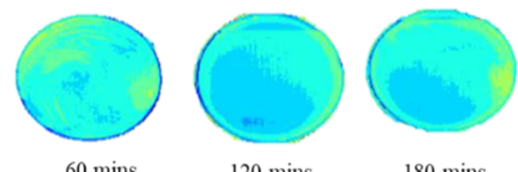

180 mins
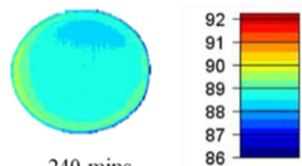

(d)

Moisture content (\%)

Figure 4. Spatiotemporal moisture content distribution maps of (a) steamed sweet potatoes, (b) fried sweet potatoes, (c) pH5-EWG, and (d) pH9EWG generated by using the optimal PLS models. (Note that the color scale of an individual food structure represents a different range of moisture (\%) content, except parts c (pH5-EWG) and d (pH9-EWG) of Figure 4.

although cooked sweet potatoes cubes remained visually intact after $4 \mathrm{~h}$ of digestion, microstructural erosion of the sweet potato matrix (i.e., cell wall separation and cell wall breakdown) after 4 $\mathrm{h}$ of digestion was observed in the center of the cube.

The moisture uptake in the $\mathrm{pH}$ 5-EWG followed the Fickian diffusion $(n=0.22)$ whereas in the $\mathrm{pH}$ 9- EWG, the water transport could not be described using a Fickian diffusion $(n=$ 0.49). The porous microstructure of the $\mathrm{pH}$ 5-EWG may enable diffusion of water as a result of the moisture concentration gradient (Fickian diffusion). As illustrated in Nyemb et al. ${ }^{19}$ and Somaratne et al., ${ }^{34}$ interconnecting empty pores of the $\mathrm{pH}$ 5EWG matrix served as pathways for diffusion of water that enters the egg gel matrix. In contrast to the $\mathrm{pH}$ 5-EWG matrix, a complex interplay between the concentration gradient of moisture and the polymer erosion due to acid and pepsin hydrolysis of the protein-gel matrix (non-Fickian diffusion) governed the water diffusion within the $\mathrm{pH}$ 9-EWG. Here, the water diffusion may be hindered by the compact microstructure of $\mathrm{pH}$ 9-EWG. Thus, the degradation of the $\mathrm{pH}$ 9-EWG by pepsin action would provide more free space between the polymer chains, which makes it easier for water molecules to be mobile in the gel matrix.

However, in the presence of pepsin, no substantial dimensional changes were observed within $4 \mathrm{~h}$ of gastric digestion for both EWGs. In our previous study, we reported that the microstructural changes of the $\mathrm{pH} 5$ and $\mathrm{pH} 9$ EWGs during digestion by pepsin were observable only within a very thin region (less than $500 \mu \mathrm{m}$ length) of the EWG near the surface in contact with the gastric fluid-pepsin solution over the $2 \mathrm{~h}$ of digestion. ${ }^{35}$ Thus, in these experimental conditions, even though the EWG cylinders had not completely disintegrated during simulated digestion, microstructural changes may have occurred within the gel matrix during gastric digestion.

Impact of Food Structures on Diffusion Kinetics of Acid during Gastric Digestion. The acid concentration ratio data as a function of the digestion time $(t)$ were fitted into the Fick's second law and the power law models as listed in equations 1 and 2, respectively (Figure 7). The results of the model parameters and the $R^{2}$ are listed and compared in Table 6 .

The acid diffusion based on the Fick's second law model provided a good fit for almost all of the data sets $\left(R^{2}>0.97\right)$, with the exception of steamed sweet potatoes $\left(R^{2}=0.85\right)$. The food type significantly affected the diffusion kinetics of acid during gastric digestion $(p<0.05)$. There is a trend of significant $(p<0.05)$ faster acid effective diffusivity in fried sweet potatoes $\left(3.2 \pm 0.2 \times 10^{-9} \mathrm{~m}^{2} / \mathrm{s}\right)$ and slower diffusivity in steamed sweet potatoes $\left(1.6 \pm 0.4 \times 10^{-9} \mathrm{~m}^{2} / \mathrm{s}\right)$. Mennah-Govela and Bornhorst $^{2}$ has shown that the higher acid diffusivity inside the fried sweet potatoes is related to their interconnected porous microstructure compared to the compact, dense cellular microstructure of steamed sweet potatoes.

Moreover, it can be observed that for steamed and fried sweet potatoes, the trends of water and acid diffusivities were not equivalent. For example, in fried sweet potatoes, the diffusivity of 


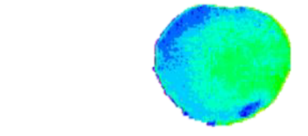

Digestion times 0 mins

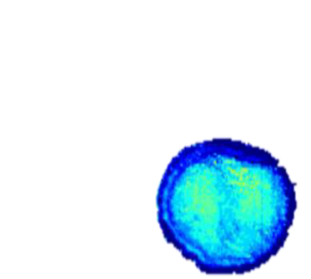

Digestion times 0 mins

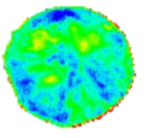

10 mins

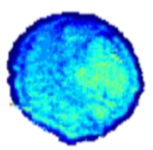

10 mins

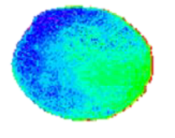

20 mins

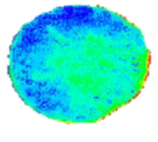

40 mins

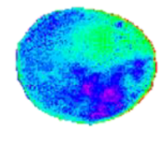

60 mins

(a)

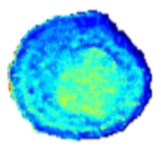

20 mins

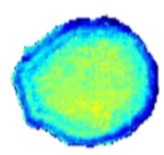

40 mins

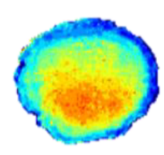

60 mins (b)

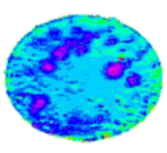

20 mins

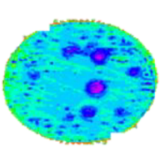

40 mins

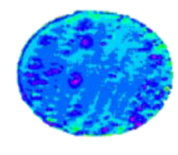

$10 \mathrm{mins}$

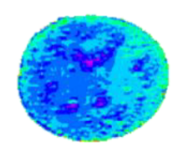

0 mins

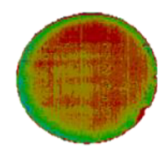

Digestion times 0 mins

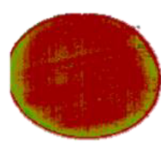

10 mins

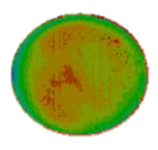

20 mins

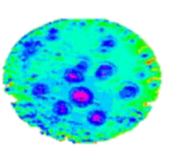

$60 \mathrm{mins}$

(c)

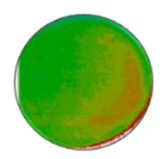

40 mins

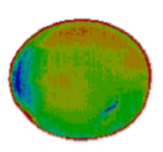

60 mins

(d)

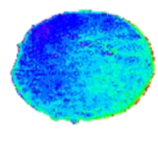

$120 \mathrm{mins}$

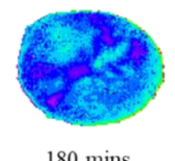

.

\section{.}

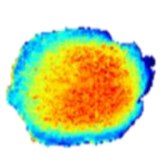

120 mins

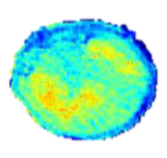

$180 \mathrm{mins}$

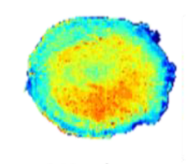

240 mins

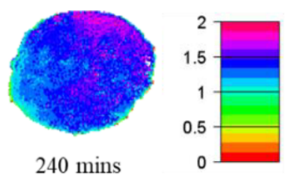

Total acid content (mg $\mathrm{HCl} / \mathrm{g}$ of sample)

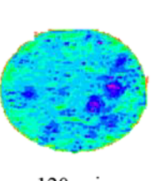

$120 \mathrm{mins}$

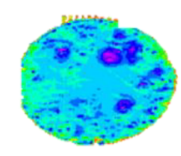

180 mins

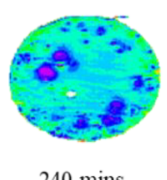

240 mins

Total acid content (mg $\mathrm{HCl} / \mathrm{g}$ of sample)

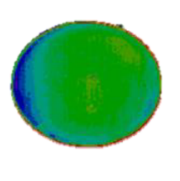

$120 \mathrm{mins}$
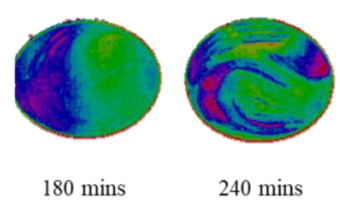

240 mins

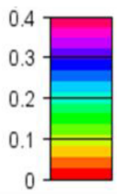

Total acid content (mg $\mathrm{HCl} / \mathrm{g}$ of sample)

Figure 5. Spatiotemporal acid content distribution maps of (a) steamed sweet potatoes, (b) fried sweet potatoes, (c) pH5-EWG, and (d) pH9-EWG generated by using the optimal PLS models. (Note that the color scale of an individual food structure represents a different range of acid (mg HCl/g of sample) content).

acid $\left(3.2 \pm 0.2 \times 10^{-9} \mathrm{~m}^{2} / \mathrm{s}\right)$ was higher than that in steamed sweet potatoes $\left(1.6 \pm 0.4 \times 10^{-9} \mathrm{~m}^{2} / \mathrm{s}\right)$. In contrast, in steamed sweet potatoes, the diffusivity of water $\left(2.2 \pm 0.8 \times 10^{-9} \mathrm{~m}^{2} / \mathrm{s}\right)$ was higher than that in fried sweet potatoes $\left(1.9 \pm 0.5 \times 10^{-9}\right.$ $\mathrm{m}^{2} / \mathrm{s}$ ) during gastric digestion. Similarly, the spatiotemporal distribution patterns of water (Figure $4 a, b$ ) and acid (Figure $5 \mathrm{a}, \mathrm{b}$ ) were also not equivalent within steamed and fried sweet potatoes. These results are confirmed by the previous study of Mennah-Govela and Bornhorst. ${ }^{2}$ These authors reported that there was not a consistent trend of water and acid diffusivity across sweet potatoes with different structures, and thus they should be estimated separately. However, the reason for different trends of moisture and acid diffusivities across steamed and fried sweet potatoes is not clear; this merits future investigation.

Both pH 5-EWG $\left(2.4 \pm 0.1 \times 10^{-9} \mathrm{~m}^{2} / \mathrm{s}\right)$ and $\mathrm{pH}$ 9-EWG $(2.3$ $\left.\pm 0.6 \times 10^{-9} \mathrm{~m}^{2} / \mathrm{s}\right)$ had similar values of $(p>0.05) D_{\text {eff }}$ of acid. Limited information was found related to the $D_{\text {eff }}$ of acid and water within EWG matrices during simulated gastric digestion. The factors influencing acid diffusion of both EWGs might include macro-structural properties (e.g., textural properties), microstructural properties (e.g., porosity, tortuosity), electrostatic interactions between egg gel matrices and $\mathrm{H}^{+}$ions, as well as buffering capacity. Elucidation on these specific properties of EWGs that control diffusion is an area that merits future investigation.
The power law model had an acceptable $R^{2}(>0.97)$ for all the product models. The predicted diffusion behavior of acid in steamed sweet potatoes is both Fickian diffusion and erosion controlled, whereas the Fickian diffusion should be responsible for the observed acid diffusion behavior in fried sweet potatoes. Both pH 5- and pH 9-EWGs followed a Fickian acid diffusion mechanism during in vitro gastric digestion.

Limited information was found related to the mechanism of acid diffusion into food structures during simulated gastric digestion. Thus, to better elucidate the mechanisms of the disintegration of food matrices when immersed in gastric acid, the proposed HSI could be improved in the future to investigate the $\mathrm{pH}$ changes of gastric juice and associated structural changes in digested food matrices during the penetration of gastric acid within the matrix.

Performance Comparison of the Fick's Second Law and the Power Law Diffusion Models. In this study, the Fick's second law was used to predict the acid and moisture diffusivities within the food types whereas the power law model was used to identify the mechanism of diffusion. In the power law model, three types of diffusion mechanisms are proposed: pure Fick's diffusion, both erosion controlled and Fick's diffusion, and purely erosion controlled mechanism. ${ }^{26,27}$ However, in order to apply for Fick's second law, the diffusion of moisture or acid should be governed by pure Fickian diffusion with the assumption of negligible shrinkage of the food matrix during digestion. ${ }^{23}$ 


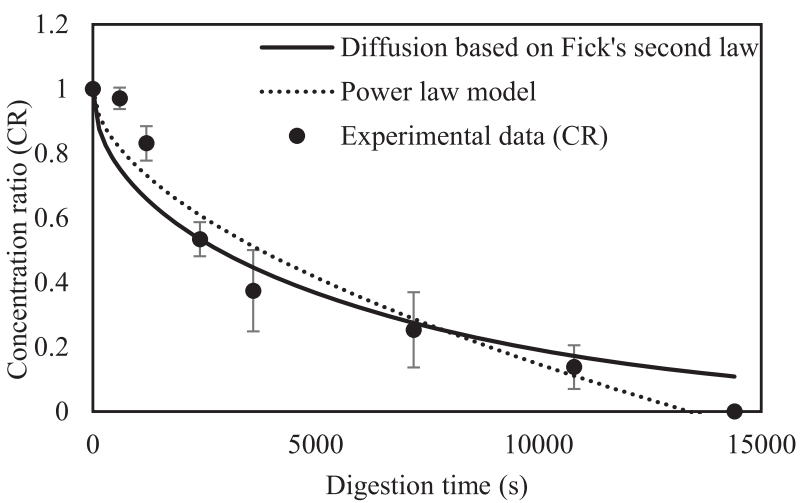

(a)

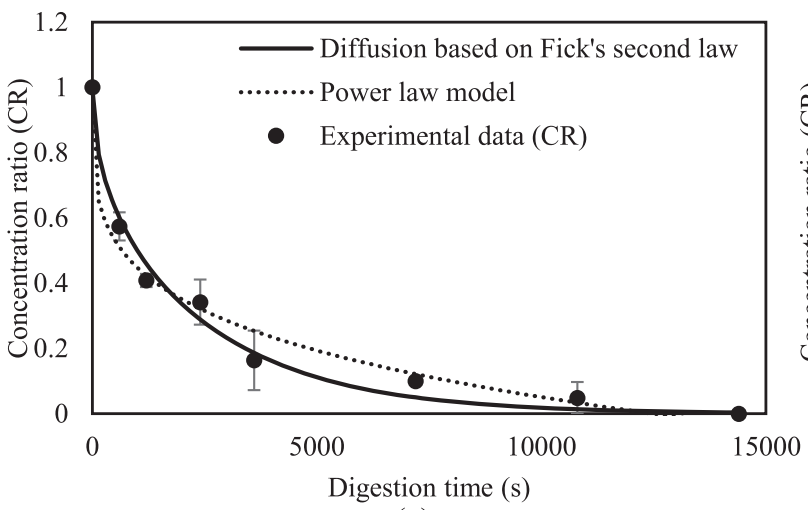

(c)

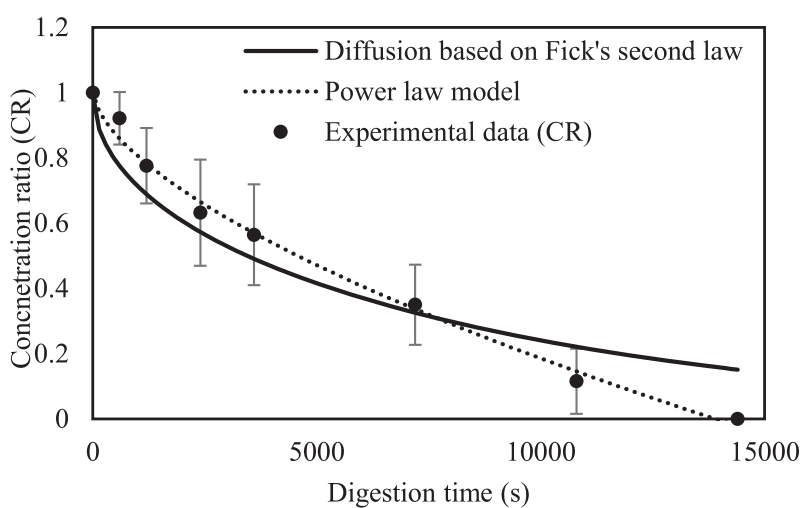

(b)

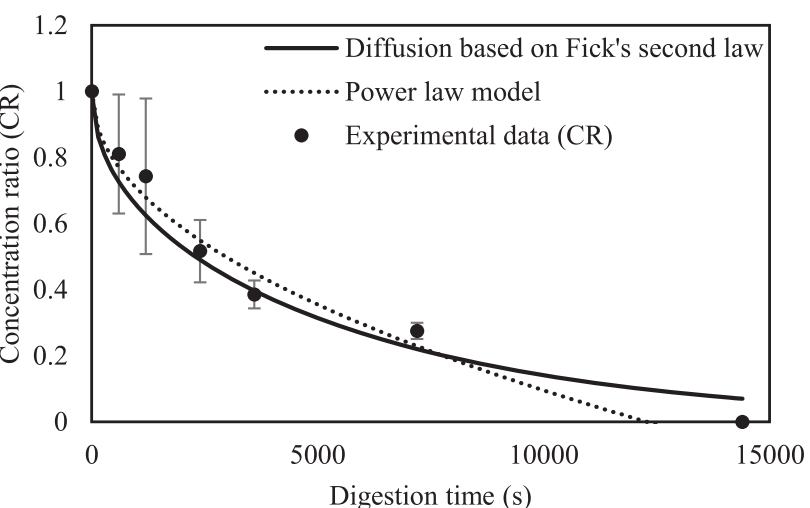

(d)

Figure 6. Plots of moisture concentration ratio as a function of digestion time (s) for the steamed sweet potatoes (a), fried sweet potatoes (b), pH5EWG (c), and pH9-EWG (d). Circles represent average experimental values $(n=3)$, and error bars represent the standard deviation of the mean. The predictions of the models of Fick's second law (eq 1) and the power law model (eq 2) are represented by solid and dashed lines, respectively.

Table 5. Rate of Moisture Diffusion $(k)$, Diffusion Exponent $(n)$, Diffusion Mechanism, and Effective Diffusivity $\left(D_{\text {eff }} \pm\right.$ Standard Deviation of $n=3$ ) for Water in Steamed and Fried Sweet Potatoes and pH 5- and pH 9-EWGs ${ }^{a}$

\begin{tabular}{|c|c|c|c|c|c|c|c|c|}
\hline & \multicolumn{5}{|c|}{ Power law model } & \multicolumn{3}{|c|}{ Fick's 2nd law model } \\
\hline & $R^{2}$ & SSE & $k$ & $n$ & Diffusion mechanism & $R^{2}$ & SSE & $D_{\text {eff }}\left(\mathrm{m}^{2} / \mathrm{s}\right) \pm \mathrm{SD}$ \\
\hline Steamed sweet potatoes & 0.94 & 0.03 & $0.006 \pm 0.003^{c}$ & $0.56 \pm 0.06^{\mathrm{ab}}$ & Erosion controlled + Fickian diffusion & 0.91 & 0.08 & $2.2 \pm 0.8 \times 10^{-9 b}$ \\
\hline Fried sweet potatoes & 0.99 & 0.01 & $0.003 \pm 0.001^{\mathrm{d}}$ & $0.62 \pm 0.06^{\mathrm{a}}$ & Erosion controlled + Fickian diffusion & 0.92 & 0.06 & $1.9 \pm 0.5 \times 10^{-9 c}$ \\
\hline pH5-EWG & 0.98 & 0.08 & $0.106 \pm 0.014^{\mathrm{a}}$ & $0.22 \pm 0.05^{c}$ & Fickian diffusion & 0.98 & 0.02 & $5.6 \pm 1.4 \times 10^{-9 a}$ \\
\hline pH9-EWG & 0.97 & 0.03 & $0.011 \pm 0.004^{\mathrm{b}}$ & $0.49 \pm 0.04^{\mathrm{b}}$ & Erosion controlled + Fickian diffusion & 0.94 & 0.05 & $2.1 \pm 0.1 \times 10^{-9 b}$ \\
\hline
\end{tabular}

${ }^{a} R^{2}=$ coefficient of determination, SSE = error sum of squares; $\mathrm{a}-\mathrm{d}$ : means within each column followed by different superscript letters are significantly different $(p<0.05)$.

However, the microstructural changes due to the diffusion of gastric acid and moisture are important aspects of manipulating the rates of gastric acid and moisture diffusivity from different food matrices. ${ }^{2,9,10}$ These microstructural changes could modify the acid and enzyme diffusion paths during the digestion process and, as a consequence, change the values of the acid and moisture effective diffusion coefficients obtained using the Fick's law models. This fact is supported by the results of this study. Results indicate that moisture and acid diffusivities within some products did not follow the pure Fickian diffusion. More specifically, both erosion-controlled and Fickian diffusions govern the diffusion of moisture (e.g., steamed sweet potatoes, fried sweet potatoes, and $\mathrm{pH}$ 9-EWG) and acid (e.g., steamed sweet potatoes) within the food structure during gastric digestion. Interestingly, if the diffusion mechanism is governed by erosion-controlled and Fickian diffusions, then the data set was fitted with the Fick's law model with low $R^{2}$. For examples, the Fick's law model provided a moderate fit for diffusion of moisture into steamed sweet potatoes, fried sweet potatoes, and $\mathrm{pH}$ 9-EWG $\left(R^{2}>0.91\right)$ compared to $\mathrm{pH}$ 5-EWG $\left(R^{2}=0.98\right)$ because diffusion of moisture into steamed sweet potatoes, fried sweet potatoes, and $\mathrm{pH}$ 9-EWG was regulated by the both erosion -controlled and Fickian diffusion mechanisms. In addition to that, the Fick's law model provided a good fit for diffusion of acid into fried sweet potatoes, $\mathrm{pH}$ 5-EWG, and $\mathrm{pH} 9$ EWG $\left(R^{2}>0.97\right)$, with the exception of steamed sweet potatoes $\left(R^{2}=0.85\right)$, because diffusion of acid into steamed sweet potatoes was regulated by both erosion-controlled and Fickian diffusion mechanisms. Therefore, future works should take into account microstructural degradation when modeling the gastric juice diffusion process. In addition to that, elucidation on the specific microstructural changes and subsequent nutrient release that controls the diffusion of gastric juice into differing food matrices is an area that merits future investigation. 


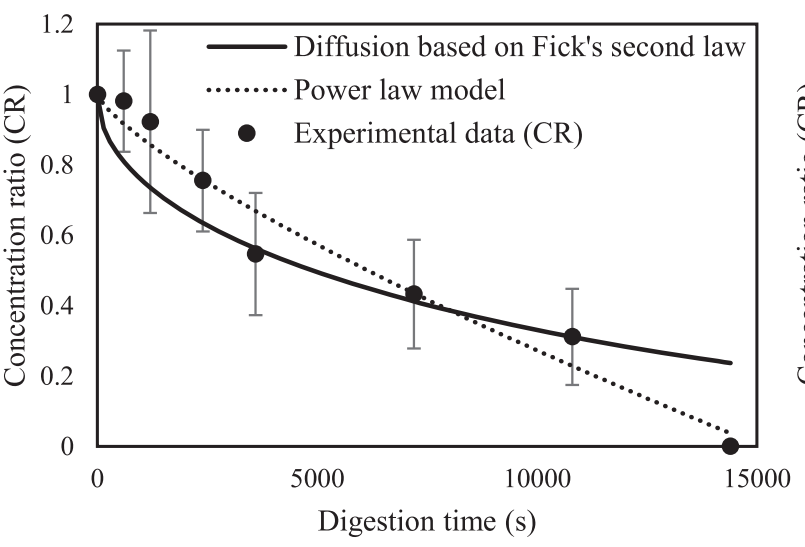

(a)

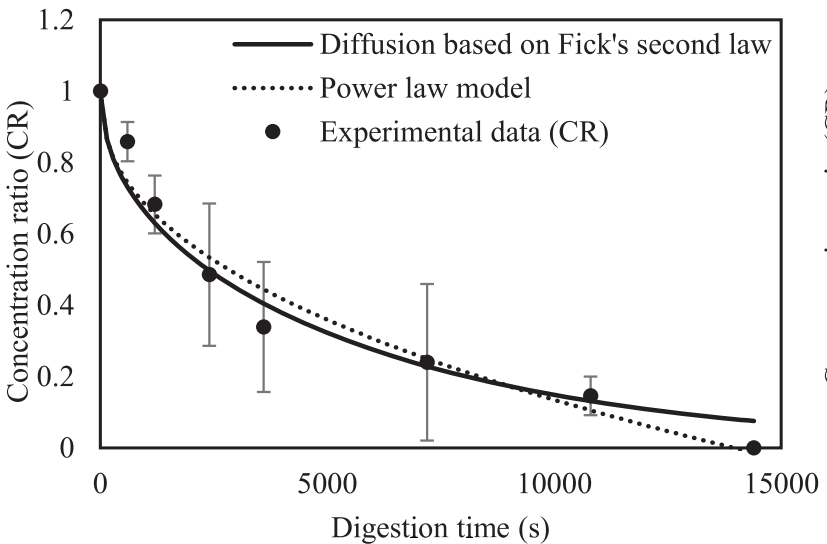

(c)

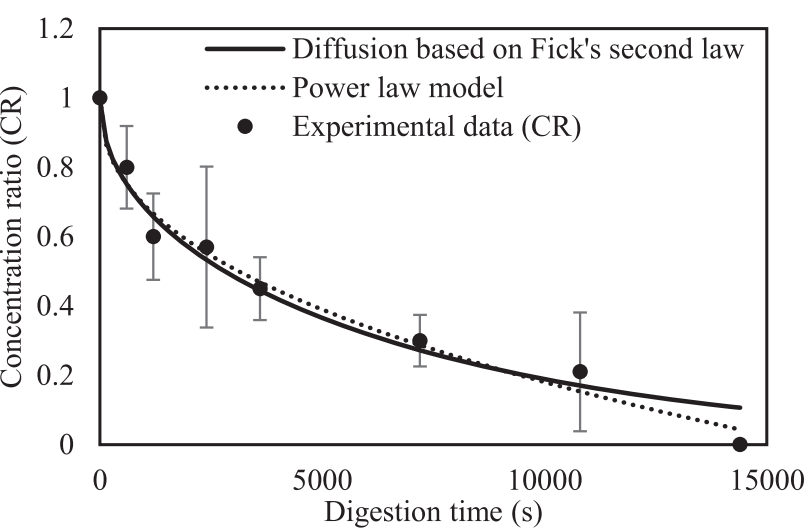

(b)

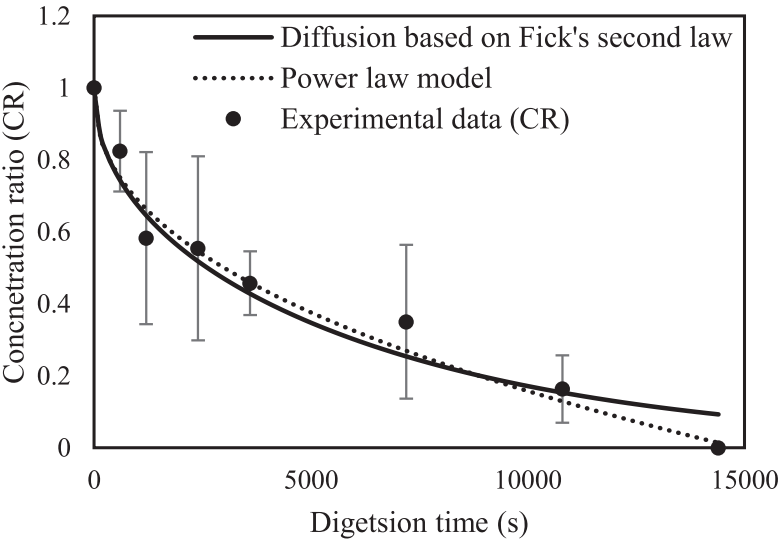

(d)

Figure 7. Plots of acid concentration ratio as a function of digestion time (s) for the steamed sweet potatoes (a), fried sweet potatoes (b), pH5-EWG (c), and pH9-EWG (d). Circles represent average experimental values $(n=3)$ and error bars represent the standard deviation of the mean. The predictions of the models of Fick's second law (eq 1) and the power law model (eq 2) are represented by solid and dashed lines, respectively.

Table 6. Rate of Acid Diffusion $(k)$, Diffusion Exponent $(n)$, Diffusion Mechanism, and Effective Diffusivity $\left(D_{\text {eff }} \pm\right.$ Standard Deviation of $n=3$ ) for Water in Steamed and Fried Sweet Potatoes and pH 5- and pH 9-EWGs ${ }^{a}$

\begin{tabular}{|c|c|c|c|c|c|c|c|c|}
\hline & \multicolumn{5}{|c|}{ Power law model } & \multicolumn{3}{|c|}{ Fick's 2nd law model } \\
\hline & $R^{2}$ & SSE & $k$ & $n$ & Diffusion mechanism & $R^{2}$ & SSE & $D_{\text {eff }}\left(\mathrm{m}^{2} / \mathrm{s}\right) \pm \mathrm{SD}$ \\
\hline Steamed sweet potatoes & 0.97 & 0.03 & $0.0006 \pm 0.0003^{c}$ & $0.76 \pm 0.044^{\mathrm{a}}$ & Erosion controlled + Fickian diffusion & 0.85 & 0.11 & $1.6 \pm 0.4 \times 10^{-9 c}$ \\
\hline Fried sweet potatoes & 0.98 & 0.01 & $0.016 \pm 0.0120^{\mathrm{a}}$ & $0.44 \pm 0.05^{b}$ & Fickian diffusion & 0.97 & 0.02 & $3.2 \pm 0.2 \times 10^{-9} \mathrm{a}$ \\
\hline pH5-EWG & 0.97 & 0.02 & $0.016 \pm 0.0002^{b c}$ & $0.43 \pm 0.03^{b}$ & Fickian diffusion & 0.97 & 0.02 & $2.4 \pm 0.1 \times 10^{-9 b c}$ \\
\hline pH9-EWG & 0.99 & 0.01 & $0.016 \pm 0.0002^{b c}$ & $0.44 \pm 0.05^{b}$ & Fickian diffusion & 0.98 & 0.02 & $2.3 \pm 0.6 \times 10^{-9} b c$ \\
\hline
\end{tabular}

${ }^{a} R^{2}=$ coefficient of determination, SSE = error sum of squares; a-d: means within each column followed by different superscript letters are significantly different $(p<0.05)$.

\section{ASSOCIATED CONTENT}

\section{S Supporting Information}

The Supporting Information is available free of charge on the ACS Publications website at DOI: 10.1021/acs.jafc.9b02430

Average initial weight of the sample, diameter and length for each food structures after cooking that were used in the static in vitro digestion model; diameter $(\mathrm{mm})$ of sweet potatoes and EWGs during $240 \mathrm{~min}$ of in vitro gastric digestion (PDF)

\section{AUTHOR INFORMATION}

\section{Corresponding Authors}

*E-mail: J.X.Singh@massey.ac.nz. Phone: +64 (06) 356 9099, ext. 84290.
*E-mail: marlon.m.reis@agresearch.co.nz. Phone: +64 (06) 356 8019.

\section{ORCID}

Aiqian Ye: 0000-0003-1048-8858

Didier Dupont: 0000-0001-5304-6561

Jaspreet Singh: 0000-0002-5301-0953

\section{Notes}

The authors declare no competing financial interest.

\section{ABBREVIATIONS USED}

$D_{\text {eff }}$ Effective Diffusivity; EWG, Egg White Gel; HIS, Hyperspectral Imaging; LVs, Latent Variables; MRI, Magnetic Resonance Imaging; PLS, Partial Least Squares; $R^{2}$, Coefficient 
of Determination; RMSE, Root Mean Square Error; SGF, Simulated Gastric Fluid; SSF, Simulated Salivary Fluid

\section{REFERENCES}

(1) Bornhorst, G. M.; Paul Singh, R. Gastric digestion in vivo and in vitro: how the structural aspects of food influence the digestion process. Annu. Rev. Food Sci. Technol. 2014, 5, 111-32.

(2) Mennah-Govela, Y. A.; Bornhorst, G. M. Mass transport processes in orange-fleshed sweet potatoes leading to structural changes during in vitro gastric digestion. J. Food Eng. 2016, 191, 48-57.

(3) Minekus, M.; Alminger, M.; Alvito, P.; Ballance, S.; Bohn, T.; Bourlieu, C.; Carriere, F.; Boutrou, R.; Corredig, M.; Dupont, D.; Dufour, C.; Egger, L.; Golding, M.; Karakaya, S.; Kirkhus, B.; Le Feunteun, S.; Lesmes, U.; Macierzanka, A.; Mackie, A.; Marze, S.; McClements, D. J.; Menard, O.; Recio, I.; Santos, C. N.; Singh, R. P.; Vegarud, G. E.; Wickham, M. S.; Weitschies, W.; Brodkorb, A. A standardised static in vitro digestion method suitable for food-an international consensus. Food Funct. 2014, 5 (6), 1113-1124.

(4) Mennah-Govela, Y. A.; Bornhorst, G. M. Acid and moisture uptake in steamed and boiled sweet potatoes and associated structural changes during in vitro gastric digestion. Food Res. Int. 2016, 88, 247-255.

(5) Lu, P. J.; Hsu, P. I.; Chen, C. H.; Hsiao, M.; Chang, W. C.; Tseng, H. H.; Lin, K. H.; Chuah, S. K.; Chen, H. C. Gastric juice acidity in upper gastrointestinal diseases. World J. Gastroenterol 2010, 16, 54965501.

(6) Kong, F.; Oztop, M. H.; Paul Singh, R.; McCarthy, M. J. Effect of boiling, roasting and frying on disintegration of peanuts in simulated gastric environment. LWT-Food Scie. and Technol. 2013, 50 (1), 32-38.

(7) Mennah-Govela, Y. A.; Bornhorst, G. M.; Singh, R. P. Acid diffusion into rice boluses is influenced by rice type, variety, and presence of $\alpha$-amylase. J. Food Sci. 2015, 80 (2), E316-E325.

(8) Ozvural, E. B.; Bornhorst, G. M. Chemical and structural characteristics of frankfurters during in vitro gastric digestion as influenced by cooking method and severity. J. Food Eng. 2018, 229, $102-108$.

(9) Van Wey, A.; Cookson, A.; Roy, N.; McNabb, W.; Soboleva, T.; Wieliczko, R.; Shorten, P. A mathematical model of the effect of $\mathrm{pH}$ and food matrix composition on fluid transport into foods: An application in gastric digestion and cheese brining. Food Res. Int. 2014, 57, 34-43.

(10) Widjaja, J. M. Kinetics of gastric juice diffusion to solid food during digestion; Master of Science Thesis; University Of California, Davis, 2010.

(11) Grover, V. P.; Tognarelli, J. M.; Crossey, M. M.; Cox, I. J.; TaylorRobinson, S. D.; McPhail, M. J. Magnetic Resonance Imaging: Principles and Techniques: Lessons for Clinicians. J. Clin. Exp. Hepatol. 2015, 5 (3), 246-55.

(12) Elmasry, G.; Kamruzzaman, M.; Sun, D. W.; Allen, P. Principles and applications of hyperspectral imaging in quality evaluation of agrofood products: a review. Crit. Rev. Food Sci. Nutr. 2012, 52 (11), 9991023.

(13) Caporaso, N.; Whitworth, M. B.; Grebby, S.; Fisk, I. D. Nondestructive analysis of sucrose, caffeine and trigonelline on single green coffee beans by hyperspectral imaging. Food Res. Int. 2018, 106, 193203.

(14) Kamruzzaman, M.; Makino, Y.; Oshita, S. Hyperspectral imaging for real-time monitoring of water holding capacity in red meat. LWTFood Scie. and Technol. 2016, 66, 685-691.

(15) Kamruzzaman, M.; Makino, Y.; Oshita, S. Parsimonious model development for real-time monitoring of moisture in red meat using hyperspectral imaging. Food Chem. 2016, 196, 1084-91.

(16) Wu, D.; Shi, H.; Wang, S.; He, Y.; Bao, Y.; Liu, K. Rapid prediction of moisture content of dehydrated prawns using online hyperspectral imaging system. Anal. Chim. Acta 2012, 726, 57-66.

(17) Zhu, Y.; Zou, X.; Shen, T.; Shi, J.; Zhao, J.; Holmes, M.; Li, G. Determination of total acid content and moisture content during solidstate fermentation processes using hyperspectral imaging. J. Food Eng. 2016, 174, 75-84.

(18) Latimer, G. Official methods of analysis of AOAC International. AOAC International: Rockville, MD, USA. 2016.
(19) Nyemb, K.; Guérin-Dubiard, C.; Pézennec, S.; Jardin, J.; BriardBion, V.; Cauty, C.; Rutherfurd, S. M.; Dupont, D.; Nau, F. The structural properties of egg white gels impact the extent of in vitro protein digestion and the nature of peptides generated. Food Hydrocolloids 2016, 54, 315-327.

(20) Jalabert-Malbos, M.-L.; Mishellany-Dutour, A.; Woda, A.; Peyron, M.-A. Particle size distribution in the food bolus after mastication of natural foods. Food Quality and Preference 2007, 18 (5), 803-812.

(21) Kong, F.; Singh, R. P. Solid Loss of Carrots During Simulated Gastric Digestion. Food Biophys 2011, 6 (1), 84-93.

(22) Gardner, J.; Ciociola, A.; Robinson, M.; McIsaac, R. Determination of the time of onset of action of ranitidine and famotidine on intra-gastric acidity. Aliment. Pharmacol. Ther. 2002, 16 (7), 1317-1326.

(23) Crank, J. The mathematics of diffusion; Oxford University Press: London, 11. 1975.

(24) Ritger, P. L.; Peppas, N. A. A simple equation for description of solute release II. Fickian and anomalous release from swellable devices. J. Controlled Release 1987, 5 (1), 37-42.

(25) Ghosal, K.; Chandra, A.; Rajabalaya, R.; Chakraborty, S.; Nanda, A. Mathematical modeling of drug release profiles for modified hydrophobic HPMC based gels. Die Pharmazie 2012, 67 (2), 147-55.

(26) Russo, M. A. L.; Strounina, E.; Waret, M.; Nicholson, T.; Truss, R.; Halley, P. J. A Study of Water Diffusion into a High-Amylose Starch Blend: The Effect of Moisture Content and Temperature. Biomacromolecules 2007, 8 (1), 296-301.

(27) Therien-Aubin, H.; Baille, W. E.; Zhu, X. X.; Marchessault, R. H. Imaging of high-amylose starch tablets. 3. Initial diffusion and temperature effects. Biomacromolecules 2005, 6 (6), 3367-72.

(28) Williams, P. C.; Sobering, D. How do we do it: a brief summary of the methods we use in developing near infrared calibrations. Near infrared spectroscopy: The future waves 1996, 185-188.

(29) Pu, Y. Y.; Sun, D. W. Vis-NIR hyperspectral imaging in visualizing moisture distribution of mango slices during microwave-vacuum drying. Food Chem. 2015, 188, 271-8.

(30) ElMasry, G.; Wang, N.; ElSayed, A.; Ngadi, M. Hyperspectral imaging for nondestructive determination of some quality attributes for strawberry. J. Food Eng. 2007, 81 (1), 98-107.

(31) Rajkumar, P.; Wang, N.; Eimasry, G.; Raghavan, G. S. V.; Gariepy, Y. Studies on banana fruit quality and maturity stages using hyperspectral imaging. J. Food Eng. 2012, 108 (1), 194-200.

(32) Alam, T.; Takhar, P. S. Microstructural Characterization of Fried Potato Disks Using X-Ray Micro Computed Tomography. J. Food Sci. 2016, 81 (3), E651-64.

(33) Sumnu, S. G.; Sahin, S. Advances in deep-fat frying of foods; CRC Press: 2008.

(34) Somaratne, G., Nau, F., Ferrua, M. J., Singh, J., Ye, A., Dupont, D., Singh, R. P., Floury, Characterization of egg white gel microstructure and its relationship with pepsin diffusivity. Food Hydrocolloids. 2019, Submitted.

(35) Somaratne, G.; Nau, F.; Ferrua, M. J.; Singh, J.; Ye, A.; Dupont, D.; Singh, R. P.; Floury. In-situ disintegration of egg white gels by pepsin and kinetics of nutrient release followed by time-lapse confocal microscopy. Food Hydrocolloids 2019, 105228. 